\title{
Text sentiment in the Age of Enlightenment: an analysis of spectator periodicals
}

\author{
Philipp Koncar ${ }^{1 *}$ (D), Alexandra Fuchs², Elisabeth Hobisch², Bernhard C. Geiger ${ }^{3}$, Martina Scholger² and \\ Denis Helic ${ }^{1}$
}

\section{*Correspondence:}

philipp.koncar@tugraz.at

'Graz University of Technology, Graz, Austria

Full list of author information is available at the end of the article

\begin{abstract}
Spectator periodicals contributed to spreading the ideas of the Age of Enlightenment, a turning point in human history and the foundation of our modern societies. In this work, we study the spirit and atmosphere captured in the spectator periodicals about important social issues from the $18^{\text {th }}$ century by analyzing text sentiment of those periodicals. Specifically, based on a manually annotated corpus of over 3700 issues published in five different languages and over a period of more than one hundred years, we conduct a three-fold sentiment analysis: First, we analyze the development of sentiment over time as well as the influence of topics and narrative forms on sentiment. Second, we construct sentiment networks to assess the polarity of perceptions between different entities, including periodicals, places and people. Third, we construct and analyze sentiment word networks to determine topological differences between words with positive and negative polarity allowing us to make conclusions on how sentiment was expressed in spectator periodicals. Our results depict a mildly positive tone in spectator periodicals underlining the positive attitude towards important topics of the Age of Enlightenment, but also signaling stylistic devices to disguise critique in order to avoid censorship. We also observe strong regional variation in sentiment, indicating cultural and historic differences between countries. For example, while Italy perceived other European countries as positive role models, French periodicals were frequently more critical towards other European countries. Finally, our topological analysis depicts a weak overrepresentation of positive sentiment words corroborating our findings about a general mildly positive tone in spectator periodicals.

We believe that our work based on the combination of the sentiment analysis of spectator periodicals and the extensive knowledge available from literary studies sheds interesting new light on these publications. Furthermore, we demonstrate the inclusion of sentiment analysis as another useful method in the digital humanist's distant reading toolbox.
\end{abstract}

Keywords: Sentiment, Age of Enlightenment, Spectator periodicals credit to the original author(s) and the source, provide a link to the Creative Commons licence, and indicate if changes were made. The images or other third party material in this article are included in the article's Creative Commons licence, unless indicated otherwise in a credit line to the material. If material is not included in the article's Creative Commons licence and your intended use is not permitted by statutory regulation or exceeds the permitted use, you will need to obtain permission directly from the copyright holder. To view a copy of this licence, visit http://creativecommons.org/licenses/by/4.0/. 


\section{Introduction}

During the Age of Enlightenment (starting in the $18^{\text {th }}$ century), so-called spectator periodicals were a popular way of distributing information to a non-academic audience and providing a platform for debating a plethora of topics, such as politics, religion and literature. Originating from London, the idea of these periodicals quickly spread all across Europe through translations and imitations adapting the characteristic narrative system and micro-narrations to local context in respective countries and languages (Fuchs et al. 2019). As some periodicals questioned customs and traditions or even included public criticism, these periodicals were emotionally charged and contained opinions with polarizing sentiment.

In this paper, we leverage the sentiment conveyed in spectator periodicals to learn more about the characteristics of the Age of Enlightenment, including, for example, important topics for the people living back then, cultural idiosyncrasies as well as the textual peculiarities regarding sentiment found in the periodicals. For that, we conduct a threefold sentiment analysis on a large dataset comprising spectator periodicals written in five major European languages to shed light on: (i) the factors influencing sentiment, such as temporal aspects or topics discussed, (ii) the relations between periodicals, places as well as people, and (iii) the usage of sentiment conveying words in the literature of the $18^{\text {th }}$ century.

While text sentiment on the Web (especially in social media) and in literature has been studied extensively in recent years, respectively in computer sciences (Liu and Zhang 2012) and digital humanities (Moreno-Ortiz 2017; Sprugnoli et al. 2016; Schmidt and Burghardt 2018), we still lack a broader understanding of sentiment in texts originating from earlier, pre-digital times and conventional media. Hence, our work not only contributes to the comprehension of the Age of Enlightenment, but also demonstrates a method to analyze the literature of the $18^{\text {th }}$ century through automatic text processing.

Approach. Building upon our previous work (Koncar and Helic 2019), we analyze a publicly available and manually annotated dataset of more than 3700 issues of spectator periodicals published in French, German, Italian, Portuguese and Spanish between 1711 and 1822. Each issue deals with one or more topics (e.g., politics or marriage) and follows the genre-specific communicative structure, comprising multiple entangled narrative levels and several narrative forms (e.g., letters to the editors, dream sequences, allegories, and dialogues).

To study text sentiment, we first utilize existing sentiment dictionaries to compute the sentiment of individual issues, allowing us to investigate the development of sentiment over time, the impact of narrative forms on sentiment and how different topics had been perceived back in the Age of Enlightenment.

Second, we construct and analyze sentiment networks, in which nodes represent entities inferred from the manual annotation of the periodicals (such as the name of the periodical or its author, place names or person names) and edges signal the sentiment between these entities. These sentiment networks allow us to study, for example, the polarity relation between countries of Europe in the $18^{\text {th }}$ century.

Third, we construct sentiment word networks in which nodes represent sentiment conveying words and edges represent semantic relation between these words. We then use these networks to explore how positive and negative words are distributed over the texts and whether they appear in chunks that signal strongly polarizing views on given 
topics or whether they diffuse more evenly across larger portions of text. Additionally, we investigate the most important words expressing sentiment, allowing us to infer if periodicals focused more on positive or negative sides of discussed topics. For that, we compute basic network metrics, including (i) degree distributions and (ii) clustering coefficients to assess the distributions of words, (iii) assortativity to measure biases in semantic relations between words of similar sentiment, and (iv) centralities to find most central and important words in networks.

Findings. We observe differences in the mean sentiment conveyed in spectator periodicals between the five languages. For example, while Spanish periodicals have a consistently more negative sentiment, Italian and French periodicals have a more positive sentiment, indicating cultural dependencies on how to address important issues. The influence of narrative forms on sentiment is inconclusive, as results vary significantly across languages. Notable commonalities are positive selfportraits and rather negative utopias for all five languages. Our results on topics suggest similar dependence on language and places.

However, using the insights from our close reading experience reveals some noteworthy observations. For example, the criticism of religion in Italian and Spanish periodicals was disguised by authors through rhetorical and stylistic devices in order to avoid censorship. Further, our sentiment networks depict how so-called "untouchables", such as Dante Aligheri and Francesco Petrarca, were used to resolve negative examples in periodicals. We find distinguishable characteristics between positive and negative word usage through our sentiment word networks. For example, we observe low transitivity and a tendency towards low degrees for negative words as well as higher transitivity and a tendency for mid-range degrees for positive words. Combining these observations with the results from our centrality analysis, which depict a weak overrepresentation of positive words among top central words, we find that spectator periodicals had, in general, a mild to positive attitude towards topics of the Age of Enlightenment and used the majority of negative words distinctively to discuss critical issues.

Contributions. To the best of our knowledge, our work is the first to investigate text sentiment in spectator periodicals published during the Age of Enlightenment in such a broad scope. By combining distant reading results with insights acquired during close reading, we extend the knowledge of spectator periodicals and of this decisive period in human history. Further, we publish the code of our analysis ${ }^{1}$, opening up possibilities to learn more about the characteristics of texts originating from the $18^{\text {th }}$ century and to compare them to today's texts and media regarding, for example, the attitude towards important societal topics then and now.

\section{Related work}

The spectator press. The foundation for the journalistic genre of spectator periodicals was laid by The Tatler (1709 - 1711), The Spectator (1711 - 1714) and The Guardian (1713) which were published by Richard Steele and Joseph Addison in England and combined previously separate fields of journalism, such as political, social and scholarly information, into one genre. Therefore the spectator press was the first print-medium able to reach a broader public with a secular discourse (Melton 2001).

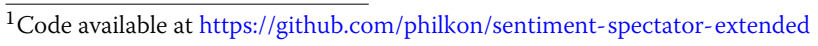


Issues of The Spectator enjoyed great popularity (circulation of around 1600 exemplars King 2018), were translated and imitated quickly and numerously all across Europe and, thus, created a new genre of periodicals and journalism (Krefting et al. 2015; PallaresBurke 2007). The first imitation by Justus van Effen, Le Misantrope (1711 - 1712), was soon followed by (partial) translations to French and German in 1714 (Gilot and Sgard 1981; Martens 2017), followed by Danish, Dutch, Italian, Portuguese, Spanish and Swedish (Gustafson 1932; Krefting 2018; Pallares-Burke 2007). Spectator periodicals significantly influenced the society regarding, for example, the image of women (Carr 2014; Messbarger 1999) or religious beliefs (Allan and Virtue 1993).

In this paper, we work with a manually annotated dataset including French, German, Italian, Portuguese and Spanish periodicals published between 1711 and 1822.

Sentiment analysis. A common task in Natural Language Processing (NLP) is sentiment analysis, aiming to investigate emotions, attitudes and opinions expressed in textual data (Pang et al. 2008). Basic methods rely on dictionaries comprising lists of words for which the sentiment or polarity (either positive or negative) is known. Popular dictionarybased methods include SentiStrength (Thelwall et al. 2010) or VADER (Hutto and Gilbert 2014), both specifically introduced for short texts originating from social media platforms, such as Twitter or Facebook. Another widely used dictionary-based method is LIWC (Pennebaker et al. 2001), aiming to identify characteristics of authors by automatically analyzing their texts. For that, authors introduced additional dedicated dictionaries capturing, for example, social relations, honesty and thinking style. Further, machine learning approaches for sentiment classification have been studied (Maas et al. 2011; Pang et al. 2002; Ye et al. 2009), including neural networks (Zhang et al. 2018). As most of studies in the field of sentiment analysis (or, in general, all NLP areas) focus on the English language, we encounter a significant scarcity of dictionaries for non-English languages. Addressing this issue opened a whole new research area known as cross-lingual sentiment classification (Chen et al. 2017), trying to transfer existing English models to other languages. Commonly, this transfer happens by using machine translation techniques to project English models to the target language or vice versa (Chen and Skiena 2014; Prettenhofer and Stein 2010; Xiao and Guo 2013).

In recent years, there has been an increased interest in applying and exploring sentiment analysis in digital humanities projects, especially in literary studies. Jannidis et al. (2016) utilize sentiment analysis for predicting happy endings in German novels from the $19^{\text {th }}$ century using a lexicon-based approach. Schmidt et al. (2018) investigate $18^{\text {th }}$ century plays of Gotthold Ephraim Lessing evaluating their results against a manually annotated text corpus. Henny-Krahmer (2018) explored the relation between sentiments and subgenres in a corpus of $19^{\text {th }}$ century Spanish American novels, differentiating direct speech and narrated text.

In our work, we rely on a basic dictionary approach introduced by Chen and Skiena (2014) as it allows for easy interpretation of results and, as opposed to other works, is available for the five languages contained in our dataset.

Networks to represent texts. Network representations of texts have been studied extensively (Amancio et al. 2012; Amancio 2015; Antiqueira et al. 2009; Cong and Liu 2014; Kulig et al. 2015; Silva and Amancio 2012). Depending on the application, there are multiple ways of how to model texts as networks. In cases where semantics are important, models connect words with semantic relations or words that co-occur in the same 
context, for example, a sentence or paragraph (Amancio et al. 2012; Véronis 2004; Widdows and Dorow 2002). If structure or style is important, words are connected based on syntactical relations, with word adjacency networks (Amancio et al. 2011; Roxas and Tapang 2010) being a well-known approach. Basically, this model links adjacent words in texts with each other, captures stylistic characteristics of texts and is language independent.

Network representations of texts have also been used for topic modeling. For example, Gerlach et al. (2018) introduced an approach based on bipartite networks of documents and words and used existing community detection methods to identify topics. Zuo et al. (2016) introduced WNTM, a topic model based on co-occurrence networks and specifically designed for sparse and short texts. Further, Liu et al. (2010) built the Topical PageRank for co-occurrence networks to extract keyphrases that summarize documents.

In this paper, we combine the network representations of spectator periodicals with sentiment analyses through two different approaches: (i) we create sentiment networks to study the relation between different entities and (ii) we construct sentiment word networks to analyze word usage patterns. While most of the presented studies focused on the English language, we investigate metrics of networks based on French, German, Italian, Portuguese and Spanish.

\section{Dataset, preprocessing and sentiment dictionaries}

We now describe the dataset we use for our analysis as well as the necessary preprocessing steps to prepare data. Further, we explain how we leverage existing sentiment dictionaries to assess the sentiment conveyed in spectator periodicals.

Dataset. We conduct our analysis on a collection of spectator periodicals that is manually annotated and curated by experts working in the fields of humanities. For that, we leverage The Spectators in the international context, a digital scholarly edition project which aims on building a central repository ${ }^{2}$ for spectator periodicals (Ertler et al. 2011; Scholger 2018). The annotated periodicals follow the XML-based Text Encoding Initiative (TEI) standard (Consortium 2020), which provides a vocabulary on how to represent texts in digital form, and are publicly available through the digital edition ${ }^{3}$.

Overall, our dataset contains 3718 issues of 67 distinct periodicals written in French (1 672 issues in 25 periodicals), German (35 issues in 4 periodicals), Italian (1 320 issues in 14 periodicals), Portuguese (44 issues in 1 periodicals) and Spanish (647 issues in 23 periodicals). Periodicals were published during different time periods allowing us to analyse a time span of 111 years. Each issue follows the same literary style and includes annotations of the levels of representation and narrative forms. The levels of representation reflect the fact that spectator periodical texts are organized according to the model of interlaced forms of discourse (Ertler 2004), which reminds of the framed construction of an Italian novel or-metaphorically-of the principle of Russian dolls. Narrative forms, such as dream sequences or metapoetical frames, were used by authors to create a more complex atmosphere of entertainment, allowing them to address the messages of virtue in a playful context and through multiple points of view.

\footnotetext{
${ }^{2}$ The central repository is hosted, preserved and presented as part of an OAIS-compliant, certified institutional repository for Humanities' research data, the Humanities' Asset Management System (GAMS); Link: https://gams.uni-graz.at. ${ }^{3}$ https://gams.uni-graz.at/spectators
} 
Table 1 Dataset statistics

\begin{tabular}{llllll}
\hline & French & German & Italian & Portuguese & Spanish \\
\hline \# Periodicals & 25 & 4 & 14 & 1 & 23 \\
\# Issues & 1672 & 35 & 1320 & 44 & 647 \\
\# Known Authors & 15 & 3 & 11 & 1 & 20 \\
\# Anon. Publications & 456 & 27 & 1 & 0 & 108 \\
\# Topics & 37 & 27 & 34 & 27 & 32 \\
\# Text Passages & 8855 & 151 & 7040 & 236 & 4008 \\
Time Span (Years) & $1711-1795$ & $1723-1765$ & $1716-1822$ & $1752-1754$ & $1735-1804$ \\
\hline
\end{tabular}

This table lists the number of periodicals, issues, known authors, anonymous publications, topics, text passages and the time spans for which our dataset contains publications, respectively for each of the five languages

Additionally, our dataset includes the following information for each issue: the author, the date and country of publication, one or multiple manually annotated topics (out of a list comprising 38 distinct topics $^{4}$ ), as well as mentioned people (including real or fictional), places (i.e., countries, cities or other geographic features) and works (e.g., other periodicals, novels or plays). The list of topics is based on existing literature focusing on the spectator periodicals (Rau 1980; Boulard 2000; Ertler 2003; Lévrier 2007; Rosa 1966) and was further adapted during the close reading process. In Table 1, we list a detailed comparison between languages and summarize statistics of the dataset. Note that due to the smaller number of German and Portuguese periodicals, we refrain from making any conclusive statements about those two languages.

Preprocessing. We start our analysis by parsing and processing the TEI encoded XML files. For each issue included in our dataset, we extract and aggregate text according to levels of representation and narrative forms into text passages (cf. Fig. 1 for an illustration). We further extract authorship information, dates of publication, manually assigned topics and mentioned people, places and works. Next, we normalize author names (e.g., Eliza Haywood and Eliza Fowler Haywood $\Rightarrow$ Eliza Fowler Haywood). If the publication date of individual issues is not known, we set it to the date of the first known publication of the corresponding periodical. E.g., if a periodical was published between $1711-1712$, then we assume that every issue was published in 1711.

Sentiment dictionaries. We determine words expressing a positive or negative sentiment by using dictionaries that have already been evaluated for French, German, Italian, Portuguese and Spanish in a previous work (Chen and Skiena 2014). There, authors extracted most frequent words of Wikipedia articles and created a knowledge graph to combine similar words of different languages through using Wiktionary, machine translation (via Google translate), transliteration links and WordNet. Starting with sentiments of English vertices based on a dictionary with 1422 (32\%) positive and 2956 (68\%) negative words, authors propagated sentiments to vertices of other languages and created dictionaries for 136 languages, each including a list of words with both a negative and a positive sentiment. For our work, we used the resulting French (4653 words; 35\% positive; 65\% negative), German ( 3974 words; $38 \%$ positive; $62 \%$ negative), Italian ( 4491 words; $36 \%$ positive; $64 \%$ negative), Portuguese (3 953 words; $35 \%$ positive; $65 \%$ negative) and Spanish (4 275 words; $36 \%$ positive; $64 \%$ negative) dictionaries.

${ }^{4}$ List of topics in alphabetical order: America (West India), Apologetic of Spain, Austria, Autopoetical Reflection, Charity, Critics on Nobility, Culture of Conversation, Economy, Education and Formation, England, Family, Fashion, Foreign Societies, France, Friendship, Germany, Happiness, Idea of Man, Image of Men, Image of Women, Italy, Law, Love, Manners and Customs, Morale, Nature, Other Countries, Passion, Philosophy, Politics, Reason, Religion, Science, Spain, Structure of Society, Superstition, Switzerland, Theatre Literature Arts. 


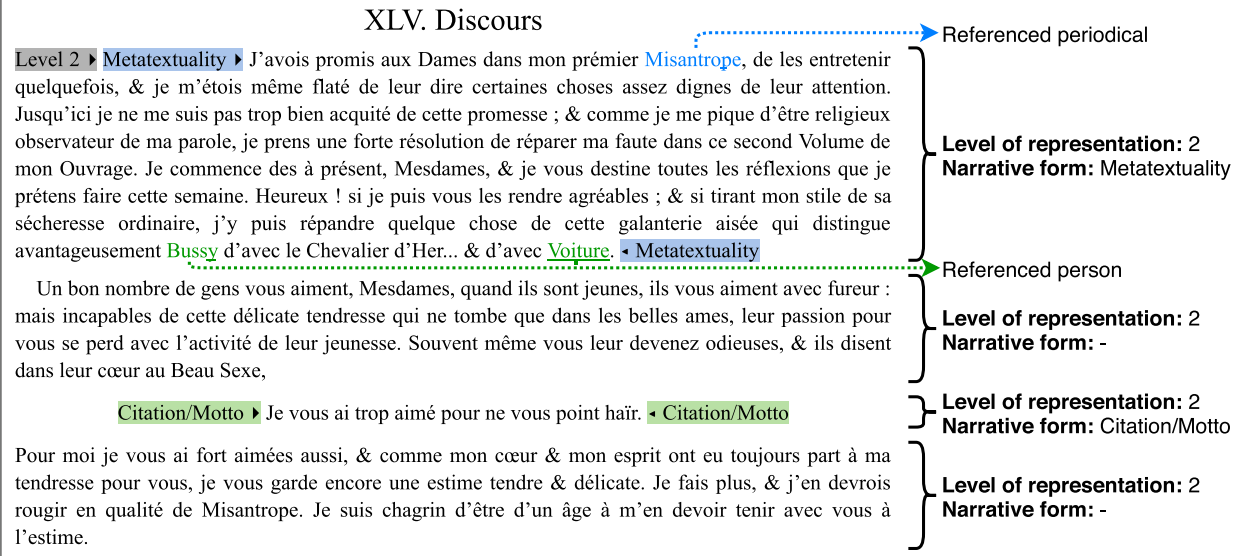

Fig. 1 Preprocessing Illustration. This figure depicts an excerpt from Le Misantrope (Vol.2\004 (1711 - 1712) by Justus van Effen; as seen in the digital edition) and illustrates how we aggregate text during preprocessing. In particular, we aggregate all text with the same level of representation and narrative form (indicated by colored labels) into text passages, respectively for each issue. In this example, we arrive at three text passages: One with level of representation 2 and narrative form Metatextuality (i.e., the first paragraph), one with level of representation 2 and narrative form Citation/Motto (i.e., the third paragraph), and one with level of representation 2 and no distinct narrative form (i.e., the second and fourth paragraph). Further, we extract mentioned periodicals (indicated with blue color), people (real or fictional; indicated with green color) and places (none in this excerpt) for our analysis

\section{Text sentiment in the spectator press}

In the first part of our analysis, we investigate the sentiment expressed in the texts of periodicals. Specifically, we ask the following questions:

(i) Sentiment over time: How did sentiment develop over time? Did historic events influence the emotions of authors and, if so, to what extent?

(ii) Sentiment of narrative forms: Did sentiment depend on the various narrative forms? For example, was a selfportrait more positive than a dream sequence?

(iii) Sentiment of topics: How have the different topics been perceived in the $18^{\text {th }}$ century? Are important social issues for the Age of Enlightenment, such as religion, more emotionally discussed than other matters?

We conduct this analysis for each of the five languages contained in our dataset and compare individual results.

Computing sentiment. Using the respective sentiment dictionaries described earlier, we compute the sentiment score $s$ of each text passage in our dataset with $s=$ $\left(W_{p}-W_{n}\right) /\left(W_{p}+W_{n}\right)$, where $W_{p}$ is the number of positive words in a text passage and $W_{n}$ is the number of negative words in a text passage. Hence, the sentiment score is a value ranging between -1 and +1 , where values close to -1 are considered as negative, values close to +1 as positive, and where values close to zero indicate a neutral sentiment.

To assess the applicability of sentiment dictionaries, we compute the coverage of sentiment words (i.e., the fraction of words in the dictionaries that are actually contained in issues), respectively for each language. For French, Italian and Spanish, we report a coverage ranging between $71 \%$ and $76 \%$, suggesting that the dictionaries extracted on modern texts are also suitable for languages of the $18^{\text {th }}$ century. In case of German and Portuguese, the coverage is lower with $36 \%$ and $25 \%$ respectively. However, we argue that this observation is due to the limited number of issues for these languages. Specifically, we cover 
$72 \%$ of negative and $79 \%$ of positive words for French, $33 \%$ of negative and $41 \%$ of positive words for German, $74 \%$ of negative and $81 \%$ of positive words for Italian, $23 \%$ of negative and $31 \%$ of positive words for Portuguese as well as $69 \%$ of negative and $75 \%$ of positive words for Spanish.

Sentiment over time. We first investigate the development of sentiment over time, following the intuition that temporal proximity to certain events, such as political unrest, impacts the emotions of authors. We report mean sentiment of text passages per year in which issues were published in the respective languages in Fig. 2. Overall, sentiment varies over time for all of the five languages. For German, Portuguese and Spanish, the mean sentiment is slightly negative, indicating that German, Portuguese and Spanish periodicals express more negative emotions. The overall mean sentiment is -0.18 for German, -0.19 for Portuguese and -0.13 for Spanish. In contrast, for French and Italian periodicals, mean sentiment is slightly positive throughout the years with an overall mean sentiment of 0.03 and 0.19 respectively.

In contrast to our initial hypothesis, we observed that no general statements can be given regarding the evolution of sentiment over time. Rather, sentiment is tightly connected to the individual periodicals, each of which has typically been published over short periods of time. We now discuss the particularities of each language in the following paragraphs.

For French periodicals (cf. Fig. 2a), we observe three peaks where sentiment is, on average, more positive compared to the remaining years. The first one of these peaks in 1728 is related to the publication of La Spectatrice, the first French spectator periodical presumably written by a woman. Therefore, the more positive sentiment in this year may be caused by the discursively created "female voice", not daring to express criticism as directly as her male colleagues. The second peak in 1753 is related to the publication of Le Spectateur moderne. Of this periodical, only one issue has been preserved and, hence,

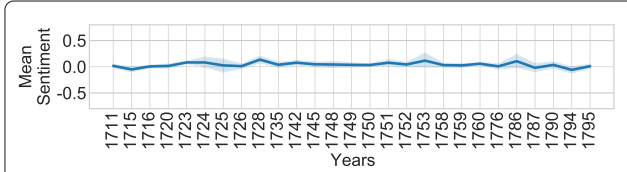

(a) French

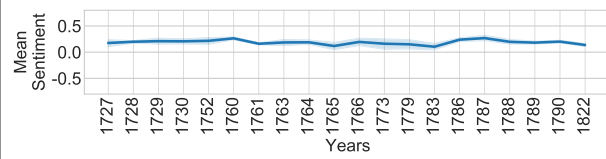

(c) Italian

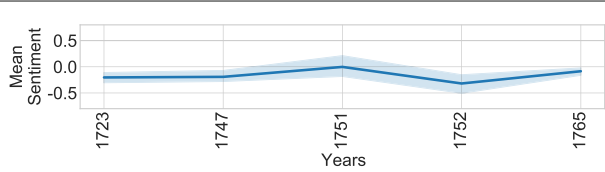

(b) German

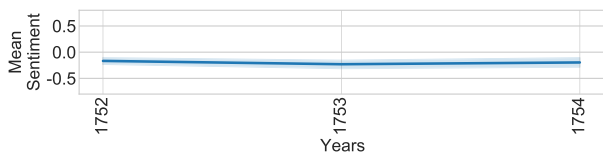

(d) Portuguese

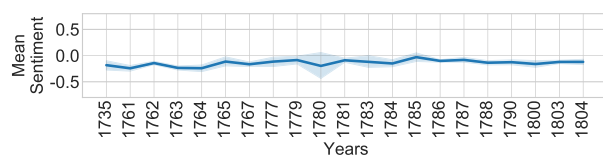

(e) Spanish

Fig. 2 Mean Sentiment Over Years. This figure illustrates the mean sentiment of text passages (with 95\% confidence intervals) over the years in which issues were published in respective languages. The mean sentiment varies over languages with French and Italian periodicals being mostly positive, whereas German, Portuguese and Spanish periodicals have mostly negative sentiment 
the peak for 1753 might not be representative. The positive peak in 1786 is caused by the publication of the first issue of Les Chiffons, an entertaining and satiric social critic. For the former two periodicals, it was the first issue of the respective periodical and we hypothesize that the authors may have used a milder tone to attract new readership.

Due to the very small quantity of text material, the sentiment over time for German periodicals (cf. Fig. 2b) is strongly depending on the individual periodicals. Each year represents only one periodical or even only one or two issues of one periodical. In this case, we note the negative sentiment in the year 1752, in which the third issue of Die Zuschauerin was published. This periodical focused on the role of women in family and society and presumably used more negative portraits and examples in the issue published in 1752.

In case of Italian periodicals (cf. Fig. 2c), we observe a particularly positive sentiment in the years 1786, 1787 and 1788 in which the periodical Donna galante ed erudita was published. This periodical mainly addressed the positive aspects of fashion, healthcare, theatre, and women. On the other hand, we speculate that the slightly more negative sentiment in the year 1765 is due to the Il Caffè authors' critical attitude towards politics and economy.

The Portugal of the $18^{\text {th }}$ century faced economic, social and political problems due to the reign of terror, fear as well as political and religious persecution. Further, censorship was widespread. The Portuguese periodical O Anonymo was published from 1752 to 1754, describing this situation with a lot of criticism, suggesting the negative mean sentiment of Portuguese periodicals (cf. Fig. 2d). The hopeless situation began to change with statesman Marquis of Pombal, who introduced many reforms based on the ideas of the Enlightenment during the second half of the $18^{\text {th }}$ century (Dill 2015).

For the Spanish periodicals (cf. Fig. 2e), we report a negative sentiment for 1735, the first year in which a Spanish periodical was published. We argue that this is due to El Duende crítico, a critical periodical similar to a pamphlet (López 2002) and published in the course of this year. The temporary and slightly more positive sentiment for the year 1762 may be caused by the publication of El Pensador, a moderate critic of the Spanish society and protégé of the Spanish King. Similarly, the slight increase in sentiment in 1765 seems to be related to the first publication of El Belianis literario a periodical that focused on literary critics. However, as this periodical is a satiric critic, making use of exaggerated praise or criticism, our sentiment analysis might not correctly infer the expressed sentiment and results may be inaccurate. We further address this issue in the limitations of our work. Another notable year for Spanish periodicals is 1785 , for which the mean sentiment is most positive. This could be due to El Censor, the most famous Spanish spectator and one of the most durable publications with extraordinary literary quality (Guinard 1973). It was one of the most critical spectator periodicals and therefore had problems with censorship. During its life in press (1781 - 1787), El Censor was prohibited twice through censorship, which led to an interruption of the publication each time. After the second break, it was again published in 1785 (Guinard 1973). As El Censor was the only Spanish spectator published in this year, we argue that the positive sentiment may result from strategies of the authors to avoid further problems with censorship by means of a lighter tone or better concealing of criticism, such as satire or indirect criticism. One could also argue that the negative sentiment in Spanish periodicals stemmed from an increased criticism of Spanish authors due to the slow progress of the Enlightenment in Spain. However, we 
argue that this is a common prejudice (Astigarraga 2015) and perhaps the more negative tone of the Spanish spectator press may be related to an inner cultural conflict between conservatives and progressives in Spain during that time (Von Tschilschke 2009). In this conflict, the spectator periodicals were a medium chosen mainly by the progressives in order to spread their reformist ideas.

Sentiment of narrative forms. As spectator periodicals deliberately avoided news, they had only limited subjects to address. In order to add variety to their texts, they embedded the same moral messages into different narrative forms, allowing authors to address the same subjects from different points of view. For example, to illustrate the importance of female virtues, the authors can use a General Account on a vicious women punished for her misconduct just as well as an Allegory representing female virtues. In other words, the message would be the same, but the sentiment could vary. In consequence, the different narrative forms are likely to vary in sentiment. To determine whether there are any trends in polarity for the specific narrative forms, we investigated them separately in our analysis.

To assess if the sentiment of a narrative form is more positive or more negative relative to the language mean (cf. Fig. 2), we standardize sentiment scores: From each sentiment value we subtract the language mean and divide by the standard deviation of the respective language.

In Fig. 3 we illustrate the mean standardized sentiment of each narrative form for each of the five languages contained in our dataset. Note that not every text passage is annotated with a narrative form. Thus, it is easily possible that all narrative forms have a sentiment that is more positive or more negative than the language mean. We observe such a case for German, for which all narrative forms have negative relative sentiment. The apparent discrepancy is resolved by the fact that text passages without annotation have positive relative sentiment.

Overall, results vary across languages. In case of French, Italian and Portuguese periodicals, the majority of narrative forms convey a more positive sentiment as compared to the language mean, while the majority of narrative forms in Spanish periodicals expressed a more negative sentiment.

Focusing on the differences across languages, we note that Utopia is rather negative compared to the language mean, for both French (mean standardized sentiment equals -0.22 ) and Spanish periodicals (mean standardized sentiment equals -0.14 ), whereas it is positive for Italian periodicals (mean standardized sentiment equals 0.10). Investigating on that, we conclude that this observation might have multiple reasons. On the one hand, Utopia was not only used to annotate the strict literary definition, which describes nearly perfect and high quality societies (i.e., we would expect a positive sentiment for this narrative form). Instead it was also used to annotate fanciful narrations. Such narrative forms are frequent in Spanish periodicals, including El Duende de Madrid comprising a complete fanciful narration in which authors of published discourses were represented as goblins in a darker setting, potentially explaining the negative mean standardized sentiment for Utopia in Spanish periodicals. On the other hand, for French periodicals the Utopia annotation is more accurate to the literary definition, but French periodicals also include dystopic narrations, explaining the negative sentiment for French. The authors of Spanish periodicals seem to have used dream sequences for such dystopic narrations, reflecting the rich literary heritage of Spanish satiric dream narrations of the baroque period (Gómez Trueba 1999) and explaining the more negative sentiment 


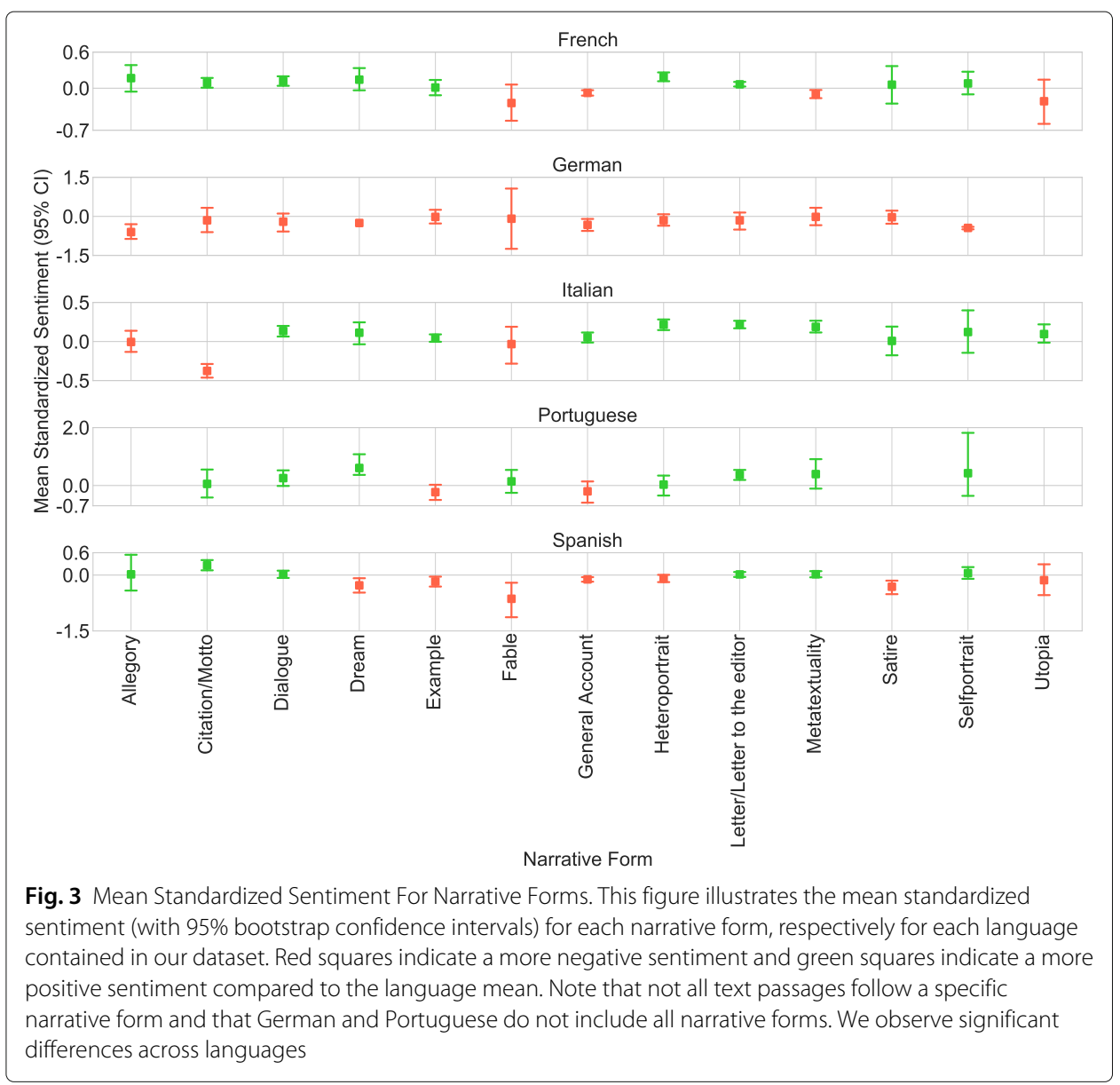

of Dream Sequences for Spanish. Regarding the more positive sentiment for Utopia in Italian periodicals, we conclude that these utopias mainly comprise dialogue series between Odysseus and various animals in the Osservatore veneto (Fuchs and Ertler 2014). Here, similar to utopias of French and Spanish, negative examples are shown, however, due to the transformation of the moral instruction to Circe's Island ${ }^{5}$, it is integrated into a harmonious scene. The moral instruction then takes place based on a striking, pleasing and nonviolent language. Some of the utopias integrated in other Italian periodicals include positive visions of the future. Overall, it turns out that utopias in the Italian periodicals are not used to scare, but to instruct in a pleasant way. Thus, the positive sentiment captures the overall positive atmosphere which is apparently a characteristic of the Italian periodicals.

The narrative form Letters or Letters to the Editor have a more positive sentiment across languages, with the exception of German periodicals. Here the mean differences are 0.06 for French, 0.22 for Italian, 0.36 for Portuguese and 0.02 for Spanish. These results are surprising to us since readers, though generally polite, also expressed their honest opinions and did not always agree with the spectators in their letters. In fact, the positive sentiment for this narrative form might be an artifact from the sentiment dictionaries we used. In the $18^{\text {th }}$ century, correspondence was still a very formal act, often related to rhetoric

"Circe" refers to the goddess of magic in Greek mythology. 
conventions (Vellusig 2000) and the dictionaries might not be able to assess correct sentiment due to their creation on modern texts.

We also note that the Selfportrait is more positive than Heteroportrait for Spanish periodicals, suggesting that authors of the periodicals as well as their correspondents tend to present themselves in a positive way, whereas they use others as examples for bad behavior. This might be related to a general human tendency of blaming others and not oneself for your own mistakes (Shaver 2012; Weiner 1995).

Sentiment of topics. We now investigate how different topics had been perceived in periodicals. For that, we standardized sentiment in a similar fashion as in the previous study on narrative forms in order to overcome the general sentiment biases of languages (cf. Fig. 2). This allows us to infer whether or not the sentiment of topics is more positive or negative compared to the language mean.

In Fig. 4 we depict the mean standardized sentiment of each topic contained in our dataset for each of the five languages. Again, sentiment varies significantly per topic over all five languages.

In the case of French periodicals, Germany and Switzerland are among the most positive topics, while, for example, Superstition and Law had been perceived more negatively compared to the French mean. For German, we find that Other Countries, followed by Happiness and Structure of Society are among the more positive topics, whereas topics related to interpersonal relationships including Love, Family as well as Image of Men are

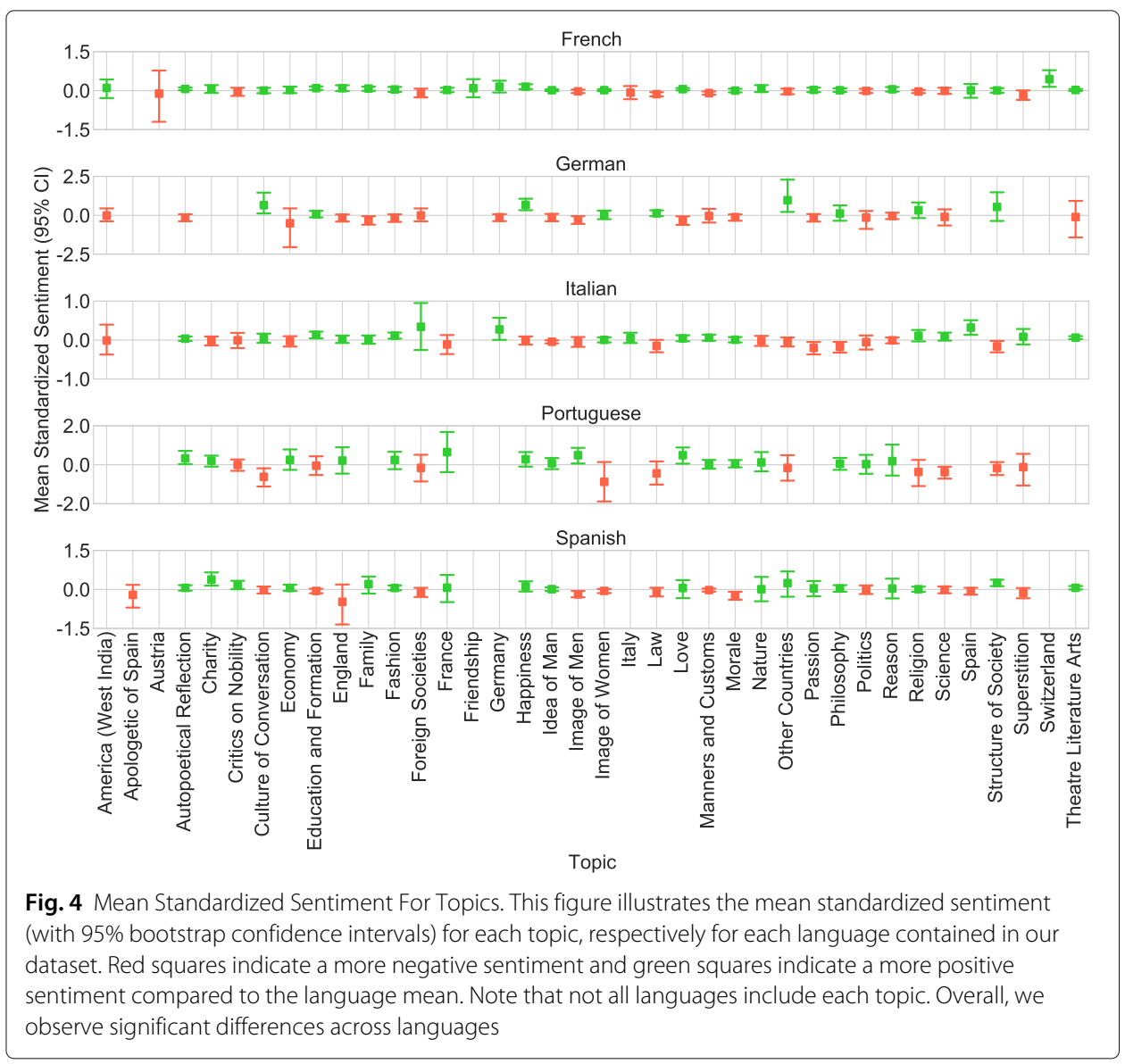


more negative compared to the language mean. For these two languages, we observe that French periodicals wrote more positively about Germany but German periodicals wrote more negatively about France. This may be due to the fact that French culture was dominant in arts and literature during the $17^{\text {th }}$ and $18^{\text {th }}$ century which, hence, was discussed polemically by other countries in Europe. Regarding Italian periodicals, we report more positive sentiment for Spain and Foreign Societies (Fuchs and Ertler 2018). The topics Passion and Philosophy comprise a more negative text for Italian periodicals when compared to their language mean. Among positive topics for Portuguese periodicals we find France, Image of Men and Love, while negative topics include Image of Women, Law and Culture of Conversation. Finally, Charity, Structure of Society and Other Countries are more positive topics for Spanish periodicals compared to its sentiment mean. Notable negative topics for Spanish include England, the Apologetic of Spain and Morale.

Analyzing the results of French in more detail, we find it surprising that the topic Image of Women has a positive mean standardized sentiment, whereas the topic Image of Men has a negative mean standardized sentiment. The discussion of gender roles is one main topic of many enlightened authors and women were often considered a deviation of the male norm (Honegger 1991; Steinbrügge 2016). Therefore, and keeping in mind the close reading experience, it would have seemed more logical to us to find a negative sentiment value for Image of Women. However, considering the plethora of different French periodicals, this observation turns out to be potentially caused by the quantitative dominance of Jean-François de Bastide's voluminous periodicals Le Nouveau Spectateur, Le Monde comme il est and Le monde. One main topic of these periodicals is the Love discourse (Fischer-Pernkopf et al.2018), which of course accompanies a more positive sentiment on the opinion of women.

For Italian, we observe that the topics Politics and Structure of Society were generally shown in a gloomy light. For example, northern Italy is governed by foreign rulers who were not perceived in a positive way, although the Italians knew how to negotiate with them. The fact that Charity and Fortune convey a negative sentiment may be explained by the description of charitable actions, which often included the example of tragic destinies. These charitable actions are often connected to the criticized structures of society and the differences between city and countryside, which becomes particularly visible in the Venetian periodicals comprising the Gazzetta veneta and L'Osservatore veneto by Gasparo Gozzi or the Gazzetta veneta by Pietro Chiari. The Italy of the $18^{\text {th }}$ Century often looked hopefully at other foreign countries due to its own backwardness. After all, it was important to imitate the foreign, supposedly more progressive societies, explaining the more positive sentiment for the topic Foreign Societies. Also notable is the positive sentiment of the topic Religion, since a certain criticism of religion is present in Italian periodicals. Especially the church representatives were sometimes criticized quite harshly. Nevertheless, the need of caution had to be stressed, in order to prevent becoming a victim to censorship. Subsequently, rhetorical methods can only be perceived at a closer look, rather than on the surface as our results suggest.

The fact that among Spanish periodicals topics such as Image of Men and Image of Women, Culture of Conversation and Manners and Costumes have a negative sentiment could be due to the fact that those were the main areas of criticism for the Spanish authors, as direct criticism of Church or the Monarchy were not allowed (Von Tschilschke 2009). Hence, social interaction and in general the society were in the center of the enlightened 
attention in Spain. The comparatively negative sentiment of the topic Apologetic of Spain seems to be due to the fact that many spectator authors were among the adversaries of the Spanish apologists. As a reaction to criticism on Spanish literature from inside and outside the country, the apologists started defending the Spanish culture no matter what. In opposition to that, the authors of El Censor, El Apologista Universal and El Corresponsal del Censor started ridiculing the apologists (Guinard 1973). Notably, as the inflexible stratification of society (Ertler 2004) was one reason of the discontent of enlightened authors in Spain, we would have expected a more negative sentiment for Structure of Society and Critics on Nobility.

\section{Sentiment networks}

Our dataset contains annotated persons, places and works. In the second part of our analysis, we leverage these annotations to find answers to the following questions:

(i) Sentiment between periodicals: How did periodicals write about other periodicals? Was the tone among periodicals supportive and appreciative, or did they also criticize each other?

(ii) Sentiment between languages and places: How had countries, cities and other places been perceived by different language communities? Was the emerging nationalism of the $18^{\text {th }}$ century reflected in periodicals?

(iii) Sentiment between people: How did authors of spectator periodicals write about other (real or fictional) people? Were authors emotional or did they write about others on a factual basis?

To answer these questions, we construct three directed sentiment networks in which nodes represent the different entities (i.e., either periodicals, places or people) and edges represent sentiment (i.e., either positive or negative). There is a directed edge from one entity to another if the former has referenced the latter in one of the related text passages. Since the manual annotation of the dataset includes a language-independent normalization (e.g., "Dieu" and "Dios" are normalized to "God"), the constructed sentiment networks summarize data from all available languages. The representation of interacting entities in the form of graphs allows for simultaneously visualizing (i) the sentiment of how entities were perceived (edge color), (ii) how often an entity referenced another entity (edge width), and (iii) how often an entity was referenced (node size). As such, we find this form of representation useful for the interpretation of the results.

Sentiment between periodicals. We start by investigating the sentiment with which periodicals refer to other periodicals. Hence, nodes in the network represent periodicals published in the different languages and all across Europe. The edges signal the mean sentiment, normalized over the mean sentiment of the referring periodical, that was expressed in the text passages where a periodical was mentioned. We depict the resulting network in Fig. 5. The two Italian periodicals Spettatore piemontese and the Spettatrice positively refer to the Filosofo alla moda, which is a translation of the French translation Le Spectateur ou le Socrate modern of the English prototype The Spectator. Further, the Filosofo alla moda has been the first periodical published in Italy and due to its popularity it was published once again in 1749 with the title Lo Spettatore italiano o sia il Socrate moderno. Opera tradotta dal francese e publicata già col titolo di Filosofo alla moda ovvero 


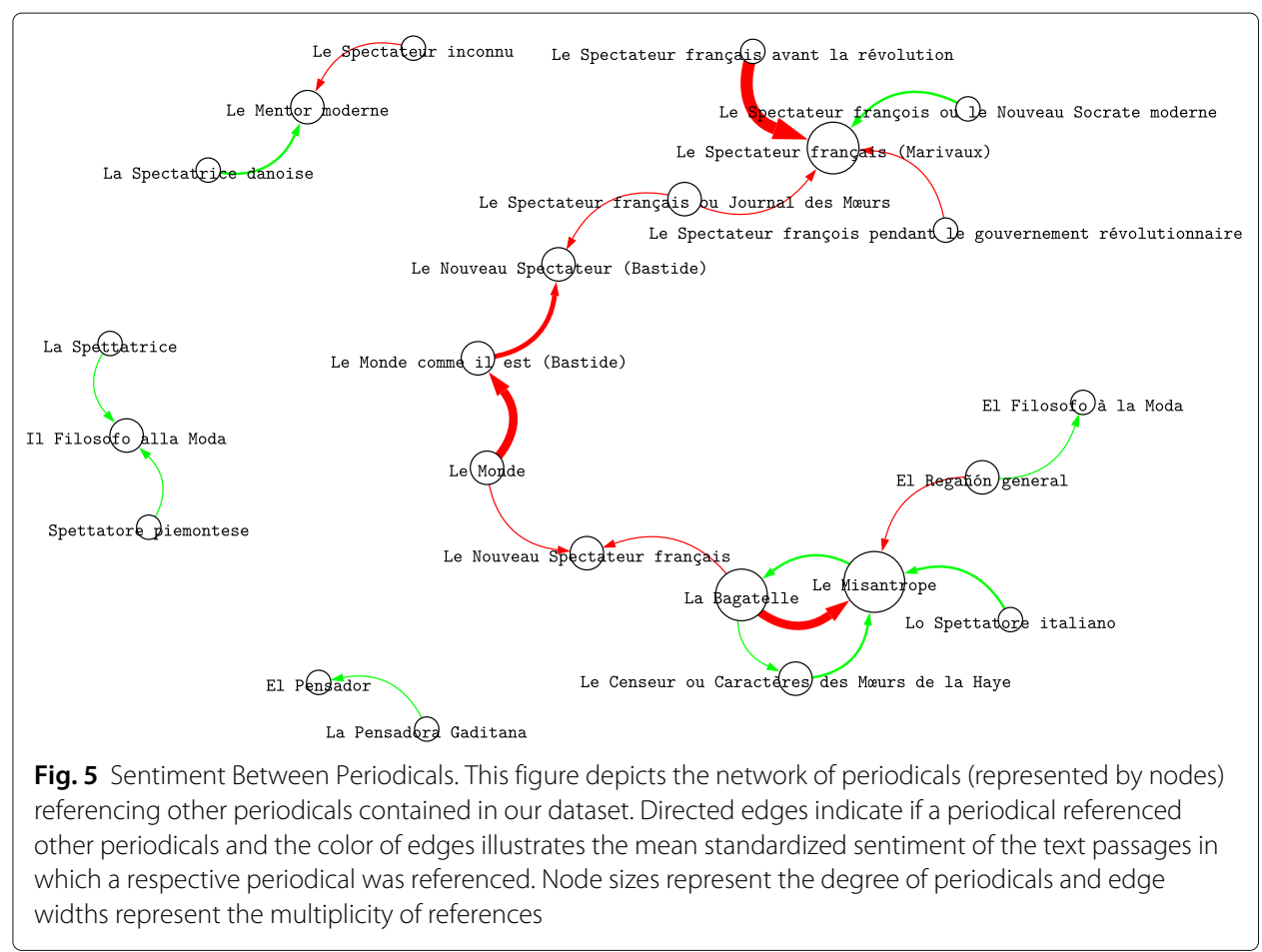

maestro universale. Therefore this text can be considered as a role model for other Italian periodicals and, as such, the text expresses positive sentiment as expected.

For Spanish periodicals, we observe a connection between La Pensadora Gaditana and El Pensador, because the publication of the presumably female La Pensadora Gaditana is a reaction to the disparaging representation of women in one of the most read Spanish periodicals, El Pensador. Despite that, we observe a positive sentiment for this references and argue, that this is potentially due to the appreciation of El Pensador, the first and a highly successful Spanish spectator periodical.

The subnetwork of French periodicals illustrates the starting point of the genre in French: Le Misantrope, the first French imitation of The Spectator published by Justus van Effen in the Netherlands, and Le Spectateur François, the first genuinely French spectator periodical published by Pierre Carlet de Marivaux. Being the first periodicals of their kind, they became the main points of reference for further French publications. Our network also shows the chain of references between the three publications of Jean-François de Bastide which were published consecutively: Le Nouveau Spectateur (1758 - 1760), Le Monde comme il est (1760) and Le Monde (1760 - 1761). The negative sentiment with which the successors refer to their predecessors is surprising, as one would expect that an author would use its previous successful work as a positive point of reference. However, we see a similar negative connection between Justus van Effen's periodicals La Bagatelle (1718 - 1719) and its predecessor Le Misantrope (1711 - 1712). Note that the reference from the earlier Le Misantrope to the later La Bagatelle stems from the fact that both periodicals were annotated on the basis of a book edition published in 1742 . These book editions often included modified texts (e.g., footnotes or prefaces), introducing the possibility of references to "future" periodicals. 
Sentiment between languages and places. We now analyze how the different language communities referenced to places, such as countries or cities. In case of this bipartite network, nodes with outgoing edges represent the languages and nodes with incoming edges represent either a country, city or fictional place. Again, we normalize sentiment over the mean of a language and connect languages to places if they have been referenced to in the respective text passages. For the purpose of better visualization, we only keep edges with at least 10 occurring references, and preserve only those nodes that are connected by the remaining edges. We depict the resulting reference network in Fig. 6.

Starting with Italian, we first notice the references to mythological Greek places, such as the Mount Parnassus or Mount Olympus, indicating that the Antiquity and the ancient mythology is still important for story-telling in the $18^{\text {th }}$ century. Very interesting are also the positive references to other countries, such as England, France, Germany, as well as cities, such as Paris or London. During the $18^{\text {th }}$ century, Italy suffered from a weak selfimage, which motivated it to imitate other European countries and cities. Furthermore, since other European cities caught up economically, Italian cities, such as Venice, lost their economic preeminence, without actually becoming economically inferior (Vaussard 2001). Thus, these other European countries and cities were generally referenced positively in spectator periodicals. The references to Asia and India are indicators for the Chinoiserie which was popular especially in the late $17^{\text {th }}$ and the $18^{\text {th }}$ century. Not only in art, but also in literature the Chinese style and the style of other countries in East Asia was imitated (Beevers 2008). The interest in distant foreign countries correlates also with the trading interests. The only country which appears in a very negative sentiment context are the Netherlands. Potentially the strong protestant context of the Netherlands was

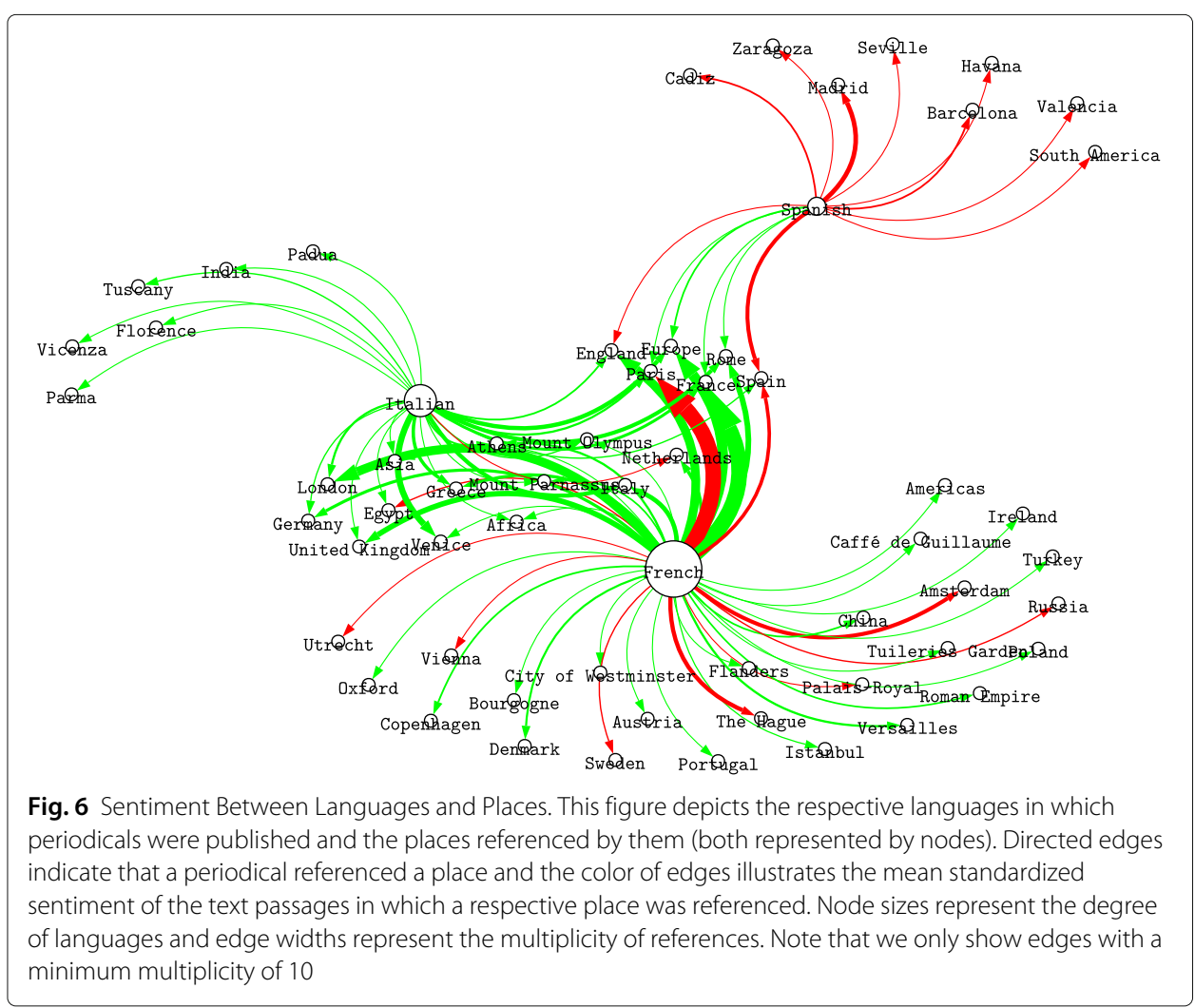


a provocation. The positive sentiment concerning England in Italian periodicals could be based on England's strong influence on the Enlightenment, which led to its perception as a role model. Another possible explanation is that the sentiment may arise from those Italian periodicals being translations of the English periodicals.

The Spanish texts generally refer to Europe, Paris, France and Rome with a positive sentiment, which reflects the cultural orientation of the Spanish Enlightenment towards other parts of Europe (Von Tschilschke 2009). The Spanish territory (which at that moment included the colonies in South America) was, however, presented with a more negative sentiment. We argue that this is related with the goal of spectator periodicals to examine and criticise the current state of their countries and societies, which often resulted in authors presenting their surroundings in a more negative way. This same explanation may be applied to the negative sentiment values we find in the French periodicals for Paris, Utrecht, The Hague and Amsterdam. These cities were the main publication places for French spectator periodicals, which is why they are in the center of criticism. Note that this observation is contrary for Italian periodicals, which refer to Italian cities positively. The clearly negative sentiment in references to Spain in French periodicals seem to be due to a cultural debate, in which French authors presented French culture as generally superior to Spanish culture (Von Tschilschke 2009) and used Spain as a negative example of anti-enlightened politics, society and literature. London, England and in general the United Kingdom have a strong influence on the Enlightenment and therefore were perceived in a more positive way in French periodicals.

Sentiment between people. Finally, we investigate references to other authors and people both real and fictional. In this network, we represent individuals as nodes and directed edges between nodes indicate that an author referenced a person. We standardize sentiment over the mean of an author and, again, keep only edges with multiplicity greater than 10. We illustrate the resulting reference network in Fig. 7.

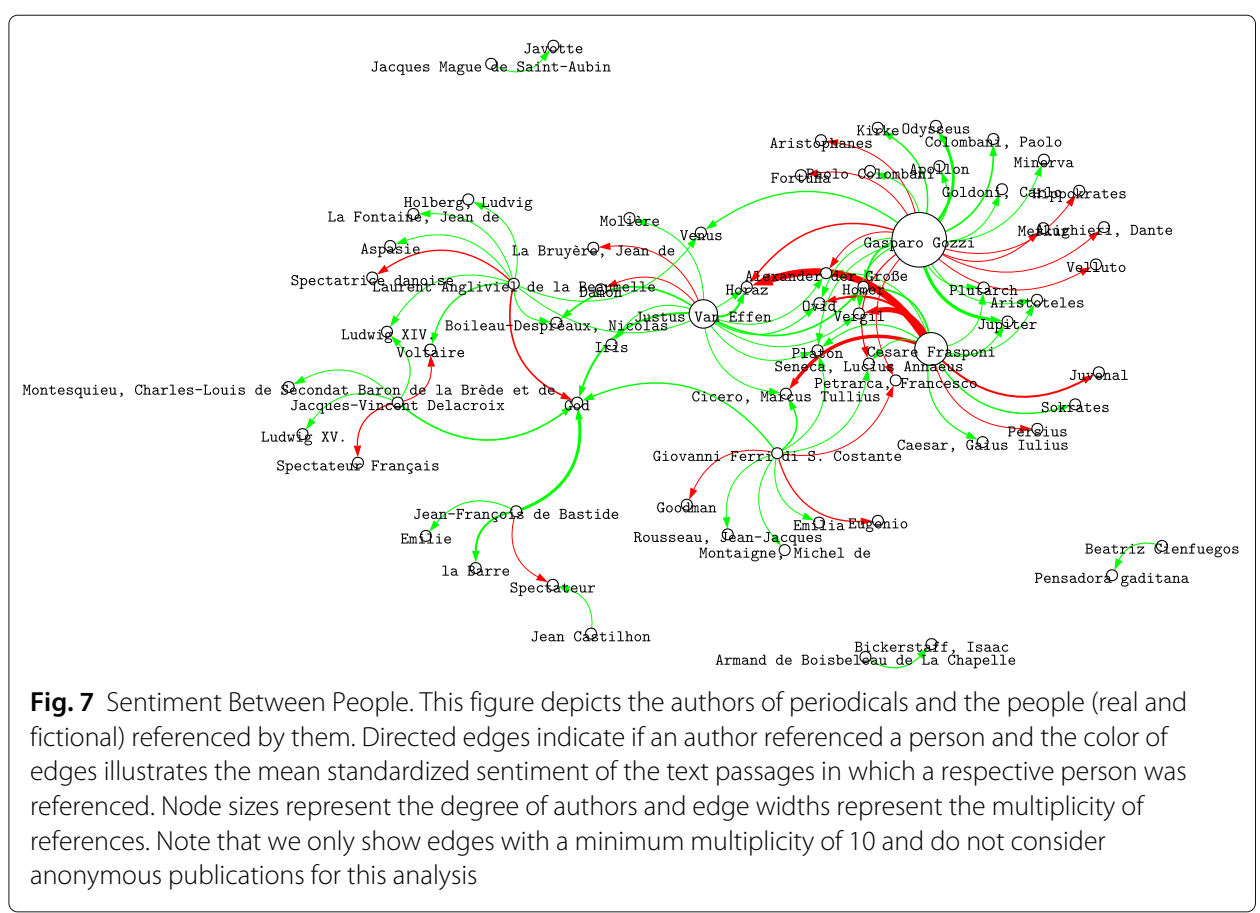


High degree nodes in the network include authors of three different Italian periodicals, each showing different references. Cesare Frasponi is the author of the Filosofo alla moda, which is a translation of the English The Spectator. Gasparo Gozzi is the author of the Gazzetta veneta and the L'Osservatore veneto and Giovanni Ferri is the author of the Spettatore italiano. The former periodical, Filosofo alla moda, includes mostly references to the Antiquity, especially to ancient philosophers and authors. However, it barely includes references to mythology. Contrary to our expectations, we observe a negative sentiment in references to Horaz, a leading Roman lyric poet in the beginnings of the Roman empire. His principle prodesse et delectare was very important for moral periodicals, which is why we would have expected a positive sentiment. Further, Italian authors barely referenced any other Italian authors due to the fact that the Filosofo alla moda is a translation from the English The Spectator.

We observe a wider range of references in the periodicals published by Gasparo Gozzi. His references to the Antiquity comprise both philosophers and mythological figures, such as Horaz, Plutarch, Platon and Apollo. The sentiment of these references is either positive or negative, depending on the message and the example signaled in the text passage the person or figure was mentioned in. A noteworthy result are the references to Fortuna, which stemmed from the superstitious fears in peoples life before the Enlightenment. People started to overcome this fear during the $18^{\text {th }}$ century, however, readers needed to be reminded once in a while by negatively reflecting this superstition. Further, Italian authors include numerous references to the own historical Italian tradition of literature, such as Petrarca, Dante and Goldoni. The reference to the latter reflect the discussion between Goldoni and Chiari about the modern Italian theatre, which captivated the whole world of theatre and literature in Italy at the time (Hösle 1993). The fact that Goldoni appears in positive contexts may provide evidence that Gozzi took sides with Goldoni during this discussion.

The periodical Spettatore italiano of Giovanni Ferri, which is the latest publication contained in our dataset (1822), contains far less references. The Querelle des Anciens et des Modernes, a literary and artistic debate at the turn of the $17^{\text {th }}$ and $18^{\text {th }}$ century, is still present in this text, but the micro-narrations with examples from the everyday life of the present are much more important and numerous. In addition, the Antiquity in the Spettatore italiano was overcome and not seen as a timeless valid model anymore. Italian authors are barely found, due to the fact that the periodical takes care of everyday life examples and is less concerned with literature. Noteworthy here is the appearance of Eugenio and Goodman, two fictional figures, which are the leading voices in a plethora of micro-narrations. We observe that these two characters seem to be connected with a negative sentiment, but, in fact, they often co-occur when there are other characters with negative sentiment. Indeed, the function of Eugenio and Goodman in these cases is to correct the wrong opinions of other figures.

Finally, we discuss why Horaz, Petrarca and Dante appear in a negative sentiment even though interpretation of results leaves us with no reliable statement. Horaz is the universal model of the spectator genre and the Italian writers Dante and Petrarca are also models in the Italian periodicals who were "untouchables". Similar to Eugenio and Goodman, their appearance in a negative context can be explained by the fact that the spectator periodicals generally created a lot of negative examples which were then solved by Horaz, or with 
reference to the Canzoniere published by Petrarca and the Divina Commedia published by Dante.

Regarding French periodicals, we observe an overlap with Italian periodicals focusing on antique names, such as Horaz, Cicero, Seneca or Homer. As these were also frequently referenced in the original English The Spectator, we argue that these references (at least partially) exist due to the literary fashion introduced by Addison and Steele, the publishers of The Spectator. In the French periodicals, these references are mainly positive, which suggests that they served as moral or literary models for the authors of spectator periodicals. In contrast, only the authors of French periodicals referred to more recently influential French authors from the $17^{\text {th }}$ century, such as Jean de La Fontaine, Jean de La Bruyère, Nicolas Boileau and Molière. Their literary works generally served as a model of orientation for authors of the $18^{\text {th }}$ century. Therefore, the negative sentiment in the references to Jean de La Bruyère by Justus van Effen probably results from the content of La Bruyères' Charactères, which incorporates mainly negative character-portraits of men to illustrate their vices. Nicolas Boileau was one of the most influential literature theorists of this era and is mainly referred to with positive sentiment. French results further clearly expose the intellectual framework of the periodicals by Jacques-Vincent Delacroix and Laurent Angliviel de La Beaumelle. La Spectatrice danoise published in Denmark by the latter represents an intermediate position between the French cultural reference framework (La Fontaine, Boileau, Voltaire) and the Danish context (Ludvig Holberg). The sentiment in both cases seems to be equally positive. Voltaire constitutes an interesting point in this network. Whereas La Beaumelle refers to him in a positive way, Delacroix' periodicals seem to have a more negative view on this polemic author.

In comparison, the Spanish periodicals seem to include rather little reference to other authors or thinkers. Only in La Pensadora Gaditana there are numerous references to the fictional (female) author of the periodical, Beatriz Cienfuegos, which is apparently due to her own discourse, but also to numerous letters of readers published in the periodical. The fact that the sentiment value for these references are mainly positive is probably due to the fact that the authors present the fictional authors in a positive way, but also many readers address them with certain respect in their letters. From the results of Les Chiffons by Jacques Mague de Saint-Aubin and Le Philosophe Nouvelliste, the French translation of The Tatler, we can draw the same conclusions.

\section{Sentiment word networks}

In the third part of our analysis, we set our focus on the textual characteristics of periodicals and investigate how sentiment was conveyed by them. Specifically, we are interested in how positive and negative words are used in the text and if there are any significant differences in their usage. We structure our analysis around the following questions:

(i) Commonly used sentiment words: What sentiment words are frequently used in periodicals, and are positive or negative words more common? Which sentiment words have stronger connectivity and which words act as mediators between other sentiment words?

(ii) Sentiment motifs: Are there common local sentiment motifs such as closed triads of sentiment words? Are there small local groups of sentiment words that frequently co-occur in close vicinity? 
(iii) Sentiment connectivity: Globally, do sentiment words tend to connect to other words of the same polarity or is there strong mixing of words with opposite sentiment? In other words, are there global clusters with a predominant sentiment?

Network extraction. We construct sentiment word networks in a similar fashion to the method introduced by Montemurro and Zanette (2013). The authors proposed to create networks in which nodes represent the most informative words in a corpus of texts and in which edges indicate that the connected words share semantic similarity.

We construct sentiment word networks as follows: Rather than extracting the most informative words, we simply restrict our attention to the words in the sentiment dictionaries that we used in our previous analyses. Then, two words are connected if they are regularly used in the same context. Specifically, as a first step we use Spacy ${ }^{6}$ and its respective language models to lemmatize texts of periodicals in order to combine inflected word forms into single representations. Further, we remove words that occur in more than $80 \%$ of all text passages and filter stop words ${ }^{7}$ introduced by the automatic translation of English sentiment dictionaries to respective languages. We then represent each word by a vector counting the number of occurrences of this word in respective text passages. Two words are finally connected if the cosine similarity between these words is significant above a $99 \%$ confidence level, where significance is computed using 1000 -fold permutation. Specifically, we repeatedly evaluate similarities on randomized frequency vectors, allowing us to compute $p$-values, defined as the fraction of times the random similarities were equal to or greater than those from the original texts, respectively for each pair of words. In Table 2 we list the top ten significant edges according to their $p$-value for each of the five networks.

We create networks respectively for each of the five languages contained in our dataset and analyze (i) degree distributions as well as degree, betweenness and closeness centralities to find commonly used sentiment words and their connectivity patterns and roles, (ii) local clustering coefficient distributions to find sentiment motifs, and (iii) degree and sentiment assortativity to analyze the sentiment connectivity.

We present results separately for positive and negative word nodes, except for assortativity, for which we consider the networks as a whole. Note that we only consider the largest connected component of each network for the remainder of our analysis (the minor components in networks have less than three nodes each; only the German network has one minor component with 29 nodes).

In Table 3 we list the number of nodes and edges of our sentiment word networks including the percentage of positive and negative nodes in each network. We observe that positive nodes represent the minority for each network, albeit with a less pronounced imbalance than in the original dictionaries. Specifically, we observe a ratio of $37 \%$ positive nodes for French, $46 \%$ positive nodes for German, 38\% positive nodes for Italian, $42 \%$ positive nodes for Portuguese and $41 \%$ positive nodes for Spanish. We depict the resulting sentiment word networks for German, our smallest network, in Fig. 8.

Commonly used sentiment words. We start with investigating the commonly used words in periodicals by reporting cumulative distribution functions (CDF) of the degree for all nodes, positive nodes only and negative nodes only in Fig. 9, respectively for each of

\footnotetext{
$\overline{{ }^{6} \mathrm{https} / / / \text { spacy.io (version used: } 2.2 .3 \text { ) }}$

${ }^{7}$ https://github.com/Alir3z4/python-stop-words
} 


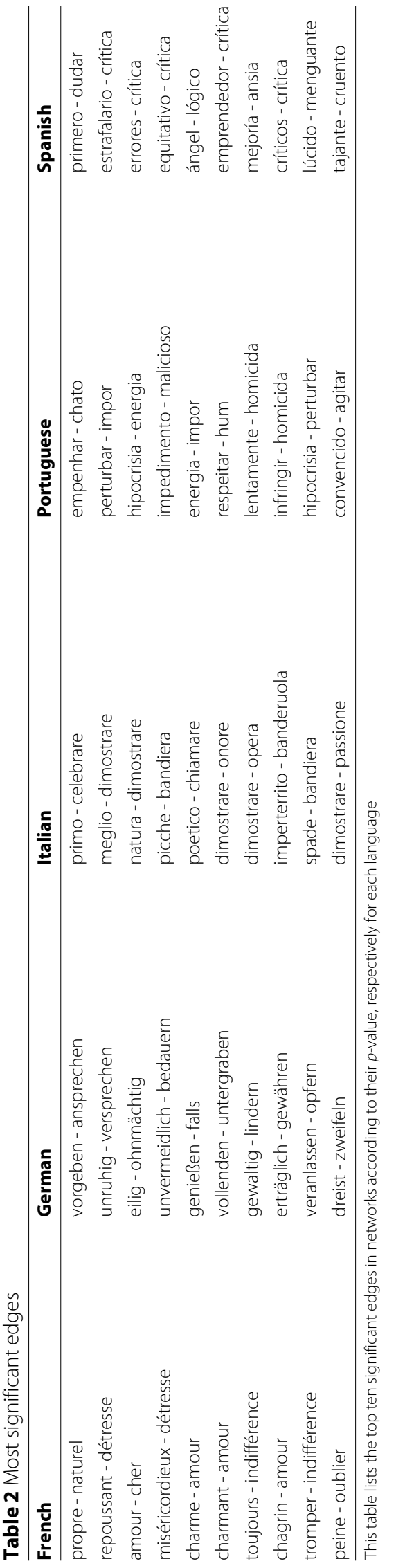


Table 3 Network sizes

\begin{tabular}{llllll}
\hline & French & German & Italian & Portuguese & Spanish \\
\hline \# Nodes & 2624 & 207 & 2711 & 685 & 2474 \\
... thereof positive & $982(37 \%)$ & $95(46 \%)$ & $1039(38 \%)$ & $286(42 \%)$ & $1007(41 \%)$ \\
... thereof negative & $1642(63 \%)$ & $112(54 \%)$ & $1672(62 \%)$ & $399(58 \%)$ & $1467(59 \%)$ \\
\# Edges & 45172 & 1589 & 44512 & 2784 & 31576 \\
\hline
\end{tabular}

This table lists the number of nodes (with ratios of positive and negative nodes) and edges of the semantic sentiment networks, respectively for each language

the five languages contained in our dataset. Our results depend on the sizes of networks. For the three larger networks of French (cf. Fig. 9a), Italian (cf. Fig. 9c) and Spanish (cf. Fig. 9e), we observe that negative nodes have higher probabilities for lower degrees in networks, whereas positive nodes have higher probabilities for mid-range degrees. In other words, negative words have a more narrow degree distribution than positive words, and the median degree of negative words is smaller than of positive words.

To test for significance of the difference between the distributions for positive and negative nodes in the networks, we conduct two-sample Kolmogorov-Smirnov tests with the commonly used significance level $\alpha=0.05$. The null hypothesis of this nonparametric test is that both samples are randomly drawn from the same distribution. Note that our samples and distributions fulfill all other assumptions for this test (independent samples, at least an ordinal level of measurement as well as continuous variables). Rejecting the null hypothesis when comparing distributions of positive and negative nodes indicates a significant difference between these distributions. To account for multiple hypothesis tests we perform Bonferroni correction (Bonferroni 1935) and divide our significance level by 5. For French, Italian and Spanish networks, the $p$-value is smaller than 0.0005 , indicating a significant difference between degree distributions of positive and negative nodes. These results suggest that a large number of negative words appear with a small number of other sentiment-conveying words and that positive words, on average, appear with a

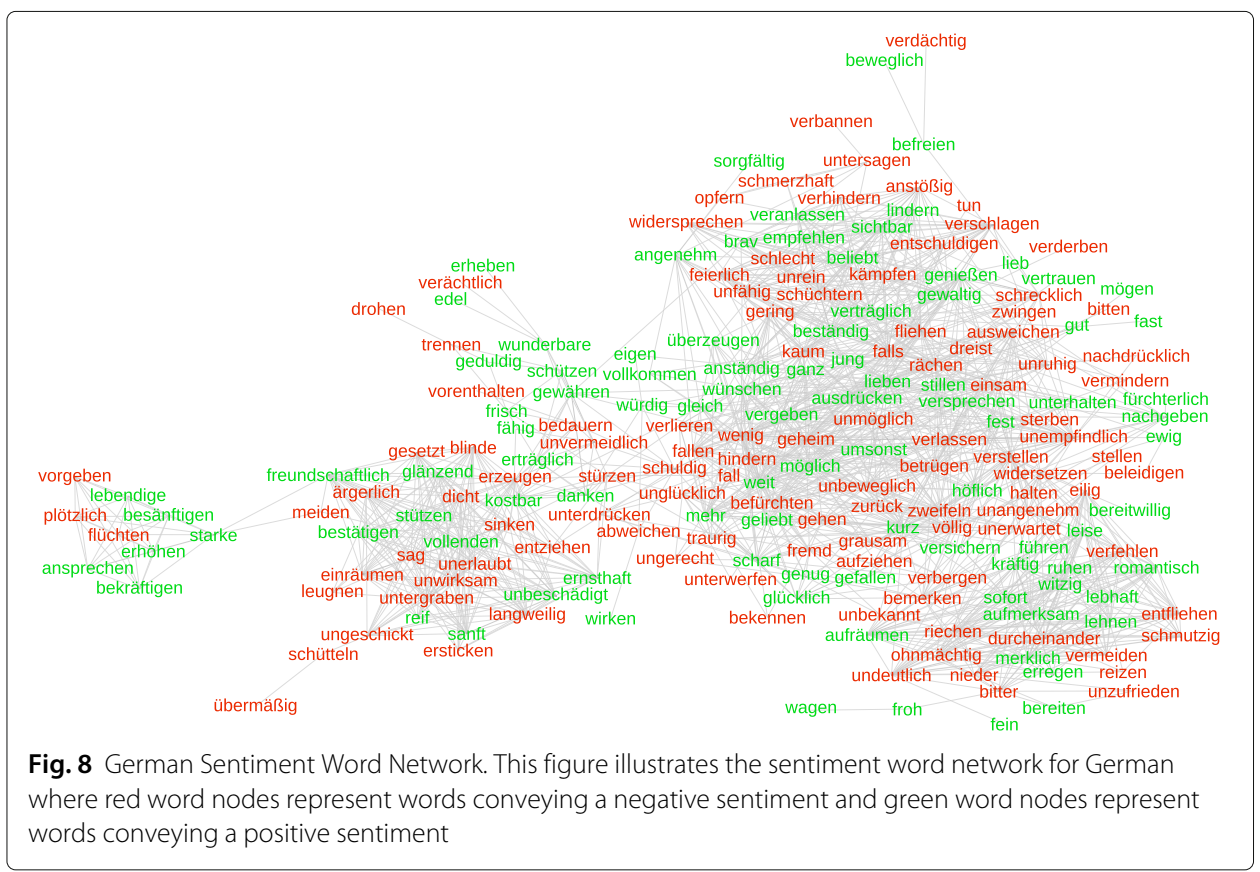




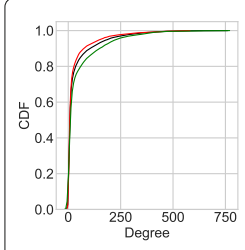

(a) French

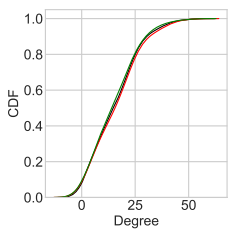

(b) German

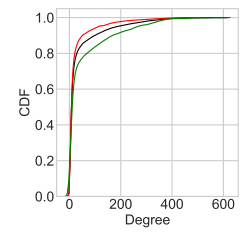

(c) Italian

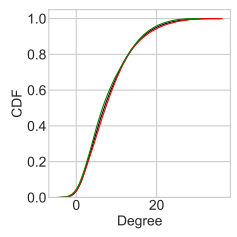

(d) Portuguese

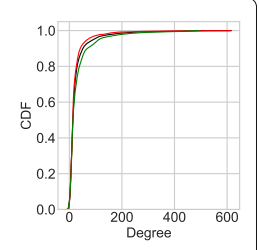

(e) Spanish

Fig. 9 Degree Distributions. This figure depicts the CDF of degrees of all nodes (black lines), positive nodes (green lines) and negative nodes (red lines) respectively for each of the five languages contained in our dataset. In case of the three larger networks, including French (cf. Fig. 9a), Italian (cf. Fig. 9c) and Spanish (cf. Fig. 9e), negative nodes have higher probability for low degrees whereas positive nodes have higher probability for mid-range degrees. The difference between degree distributions of positive and negative words is significant ( $p$-values $<0.0005$ ) for each of the three networks according to two-sample Kolmogorov-Smirnov tests. Results are different for the two smaller German (cf. Fig. 9b) and Portuguese networks (cf. Fig. 9d) for which there is no significant difference between positive and negative distributions according to a two-sample Kolmogorov-Smirnov test ( $p$-values > 0.05)

substantial number of other sentiment-conveying words. A plausible explanation for this observation in larger networks would be that the basic attitude of periodicals is positive. Also, more negative parts of the text include a larger number of various negative words specifically tailored to the given context.

In case of the two smaller networks of German (cf. Fig. 9b) and Portuguese (cf. Fig. 9d), the two-sample Kolmogorov-Smirnov test (again with $\alpha=0.05$ and Bonferroni correction) resulted in a $p$-value of 0.83 and 0.39 , respectively. We conclude that there is no significant difference between the degree distributions of positive and negative words for those two networks. We believe that this is a consequence of the small corpus size for these languages and, hence, refrain from drawing any conclusions based on these observations.

We extract commonly used sentiment words in periodicals by reporting the top 50 central words (according to the degree) for French in Fig. 10a, for German in Fig. 10d, for Italian in Fig. 10g, for Portuguese in Fig. 10j and for Spanish in Fig. 10m. Top central words for French include "bien" ("well"), "plus" ("more") and "dire" ("to say"). For German, the top central words according to degree centrality include "lieben" ("to love'), "wenig" ("little") and "fliehen" ("to flee"). In case of Italian, the top words include "molto" ("very" or "much"), "primo" ("first") and "tempo" ("time" or "period"). The most commonly used words in Portuguese periodicals include "partir" ("to leave"), "tempo" ("time") and "convencido" ("convinced"). Finally, Spanish top words comprise "solo" ("alone" pr "simple"), "parir" ("to calve" or "to lamb") and "pues" ("because" or "since").

Regarding the ratios of positive and negative words among the top 50 central words, we find mixed results for the five languages. For French, we find an equal proportion of positive and negative words. The majority of top words is negative for the smaller German (54\% negative words) and Portuguese (64\% negative words) networks, while for Italian and Spanish we report a majority of positive words with $70 \%$ and $66 \%$, respectively.

To find the sentiment words that bridge meaning and connect otherwise distant groups of sentiment words appearing together, we compute betweenness centrality for each of the five networks. We depict the top 50 central words according to betweenness centrality for French in Fig. 10b, for German in Fig. 10e, for Italian in Fig. 10h, for Portuguese in Fig. 10k and for Spanish in Fig. 10n. Top words according to betweenness centrality are 


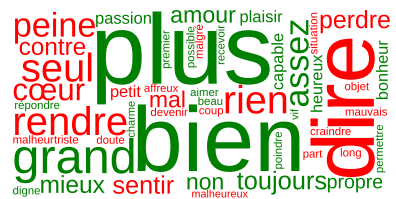

(a) French (Degree)

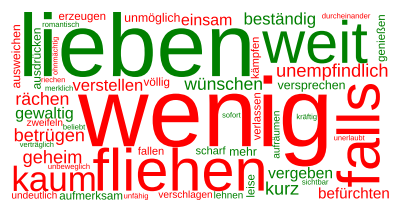

(d) German (Degree)

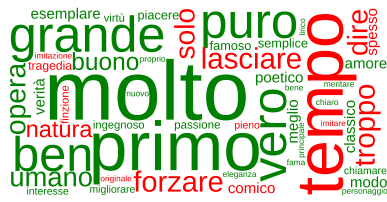

(g) Italian (Degree)

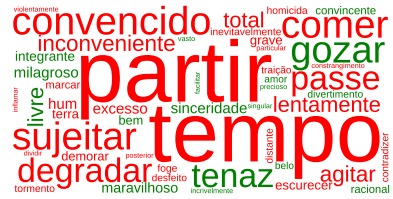

(j) Portuguese (Degree)

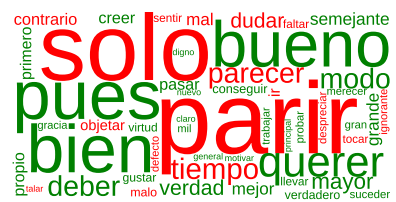

(m) Spanish (Degree)

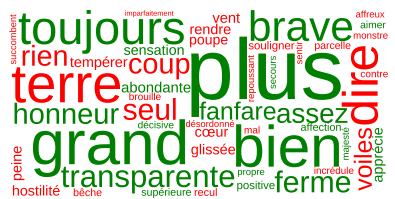

(b) French (Betweenness)

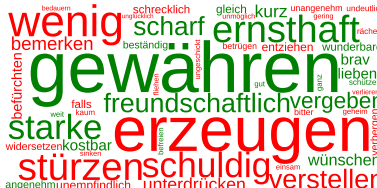

(e) German (Betweenness)

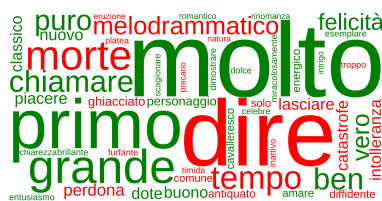

(h) Italian (Betweenness)

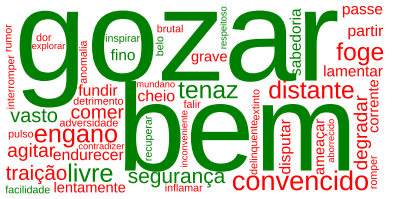

(k) Portuguese (Betweenness)

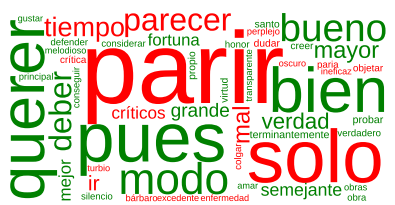

(n) Spanish (Betweenness)

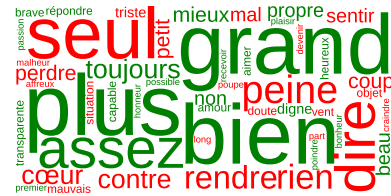

(c) French (Closeness)

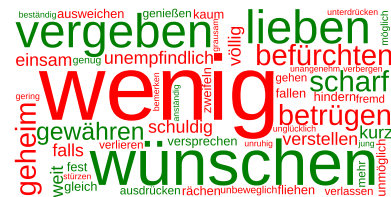

(f) German (Closeness)

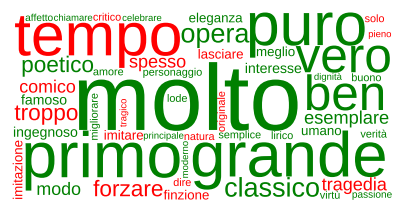

(i) Italian (Closeness)

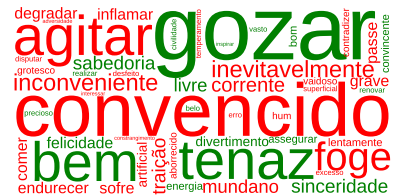

(l) Portuguese (Closeness)

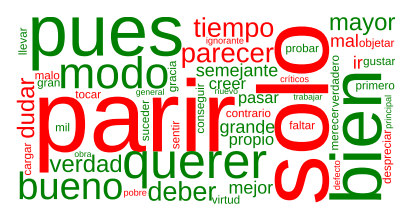

(o) Spanish (Closeness)

Fig. 10 Top Central Words. This figure depicts the top 50 most central words according to degree (left column), betweenness (center column) and closeness (right column) centrality, respectively for French, German, Italian, Portuguese and Spanish (top to bottom rows). The majority of top central words convey a positive sentiment for Italian and Spanish and a negative sentiment for French, German and Portuguese across all centrality metrics. Note that words stem from the languages of the $18^{\text {th }}$ century and respective European countries and, thus, do not relate to potentially ambiguous meanings of modern day languages

similar to those according to degree centrality. We observe notable differences for the smaller German and Portuguese networks. Top words for the former include "gewähren" ("to grant" or "to award") or "erzeugen" ("to create", "to produce" or "to make"), while top words for the latter include "bem" ("well" or "right") and "gozar" ("to enjoy").

Similar to degree centrality, the majority of top words according to betweenness centrality is positive for Italian (58\% positive words) and Spanish (62\% positive words), while we observe higher proportions of negative words for German (60\% negative words) and Portuguese (62\% negative words). For the French network, which has equal ratios according to degree centrality, we report a higher ratio of negative words with $58 \%$. These results are contrary to our previous work (Koncar and Helic 2019) with simple co-occurrence networks for which we find higher ratios of negative words among top central words for all of the three centrality metrics. 
Completing our analysis of sentiment words connecting other sentiment words, we also investigate closeness centralities. Again, we consider the top 50 central words, respectively for each of the five languages contained in our dataset. We illustrate results of closeness centrality for French in Fig. 10c, for German in Fig. 10f, for Italian in Fig. 10i, for Portuguese in Fig. 101 and for Spanish in Fig. 10o.

Top words for French, Italian and Spanish are again similar to those according to degree centrality. We observe notable differences for German, such as "vergeben" "to forgive" or "to award") or "wünschen" ("to wish"), and Portuguese, such as "agitar" ("to shake" or "to stir up") or "tenaz" ("tenacious").

Again, we observe similar results to degree centrality, with a majority of positive words for Italian (66\% positive words) and Spanish (62\% positive words), a majority of negative words for German (64\% negative words) and Portuguese (62\% negative words), as well as equal ratios of positive and negative words for French.

Finally, we depict correlations between degree, betweenness and closeness centrality in Fig. 11, respectively for each of the five languages. We compute Spearman's rank correlation coefficients among each pair of metrics and for each language and find that metrics positively correlate with each other (in all cases $p$-values are smaller than 0.0005), suggesting that words are equally central among different metrics. Our computed Spearman's correlation coefficients are ranging from 0.56 to 0.76 between degree and betweenness centrality, from 0.65 to 0.87 between degree and closeness centrality and from 0.35 to 0.69 between betweenness and closeness centrality across the three languages.

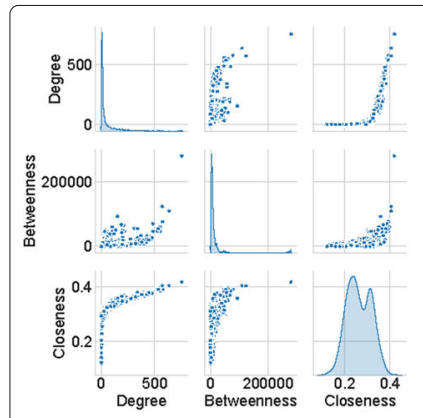

(a) French

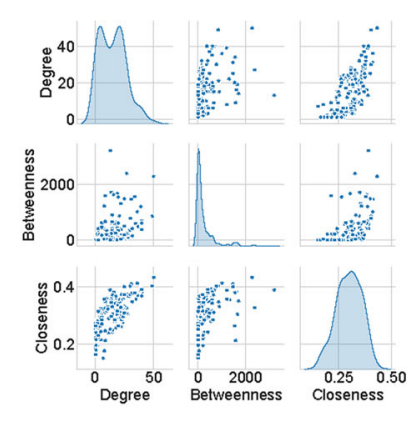

(b) German

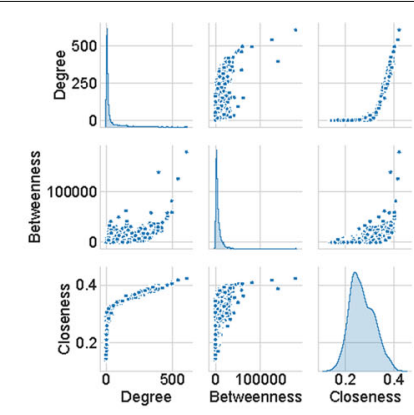

(c) Italian

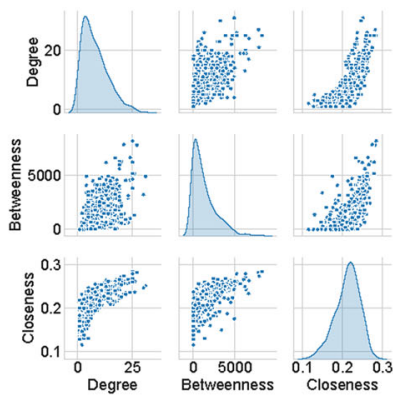

(d) Portuguese

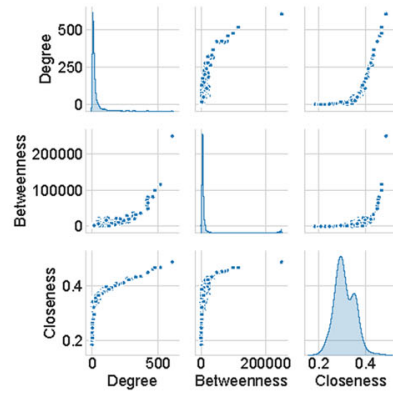

(e) Spanish

Fig. 11 Centrality Metric Correlations. This figure illustrates the correlations between the three centrality metrics, respectively for each language. For all metrics and languages, we observe a strong positive correlation, suggesting that words are similarly central across metrics 
Summarizing, the results for degree, betweenness and closeness centrality in combination with ratios of negative words in networks (cf. Table 3) suggest an overrepresentation of the minority class (positive nodes), corroborating similar results for heterophilic networks found in previous work (Karimi et al. 2018). To further investigate our observations, we compute proportion tests based on one-sample $z$-tests for each of the centrality metrics and languages. This allows us to compare the proportion of negative words among top central words to the proportion of negative words in sentiment word networks. Note that this test assumes continuous data following a normal distribution. Since we can not assume normality, we have to first test whether we can use the normal approximation method by checking if $n p \geq 10$ and $n(1-p) \geq 10$, where $n$ is the sample size (in our case 50) and $p$ is the sample mean, which we confirm for all of our cases. In 5 out of 15 cases, the ratio of negative words among top central words is significantly smaller than ratios in networks $(p$-values $<0.0005)$. The remaining 5 tests are insignificant as $p$ values are greater than 0.05 (all cases with greater ratios among top words as compared to networks), all comprising results for our two smaller German and Portuguese networks. These results suggest that there is, indeed, a slight overrepresentation of positive words among top central words.

Sentiment motifs. We look for groups of sentiment words that frequently co-occur in close vicinity by computing local clustering coefficients for each of the five languages. We depict CDF of local clustering coefficients for all nodes, positive nodes only and negative nodes only in Fig. 12, respectively for each of the five language contained in our dataset. Again, our results vary depending on the size of networks. Contrary to our expectations (following previous observations about a negative correlation between the degree and the local clustering coefficient (Ravasz and Barabási 2003)), for French (cf. Fig. 12a), Italian (cf. Fig. 12c) and Spanish (cf. Fig. 12e) networks, we observe that negative nodes have higher probabilities for lower local clustering coefficients, whereas positive nodes have higher probabilities for mid-range local clustering coefficients. This suggests that negative words have less chance to co-occur frequently with other sentiment conveying words and that positive words are more often used together in groups of similar context.

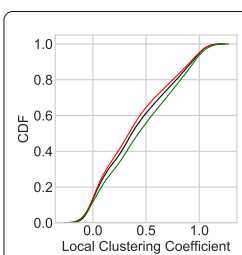

(a) French

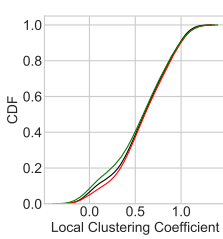

(b) German

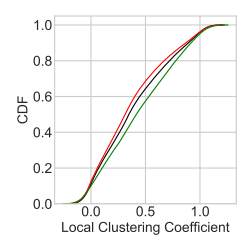

(c) Italian

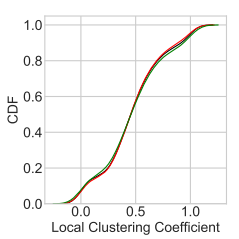

(d) Portuguese

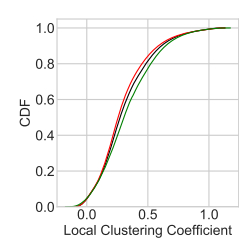

(e) Spanish

Fig. 12 Local Clustering Coefficient Distributions. This figure depicts the CDF of local clustering coefficients of all nodes (black lines), positive nodes (green lines) and negative nodes (red lines) respectively for each of the five languages contained in our dataset. In case of the three larger networks, including French (cf. Fig. 12a), Italian (cf. Fig. 12c) and Spanish (cf. Fig. 12e), negative nodes have higher probability for lower local clustering coefficients whereas positive nodes have higher probability for mid-range local clustering coefficients. The difference between local clustering coefficient distributions of positive and negative words is significant ( $p$-values $<0.0005$ ) for each of the three networks according to two-sample Kolmogorov-Smirnov tests. Results are different for the two smaller German (cf. Fig. 12b) and Portuguese networks (cf. Fig. 12d) for which there is no significant difference between positive and negative distributions according to a two-sample Kolmogorov-Smirnov test ( $p$-values $>0.05$ ) 
We again test for the significance of the difference between the distributions for positive and negative nodes by conducting Kolmogorov-Smirnov tests (again with $\alpha=0.05$ and Bonferroni correction). For the three larger networks, comprising French, Italian and Spanish, we observe $p$-values smaller than 0.005 , indicating a significant difference between distributions of positive and negative words. In case of our smaller German (cf. Fig. 12b) and Portuguese (cf. Fig. 12d) networks, the $p$-values are 0.92 and 0.97, respectively, depicting an insignificant difference between positive and negative words. Similar to degree distributions of smaller networks, we argue that this is a consequence of the small corpus size and refrain from further conclusions.

Overall, we observe a wide range of local clustering coefficients in all networks, suggesting that sentiment words form pairs as well as triangles when considering their co-occurrences.

Sentiment connectivity. We now study if words of similar frequencies and similar sentiment (i.e., positive or negative) form global clusters with a predominant sentiment in respective sentiment word networks. For that, we compute degree and sentiment assortativity.

Our results for degree assortativity of French, Italian and Spanish range between -0.10 and 0.04, depicting that high and low degree nodes connect almost randomly with each other. In case of German and Portuguese, networks are slightly more assortative, with values of 0.22 and 0.32 , respectively. This observation is contrary to previous findings, where (Cantwell and Newman 2019) depicted slightly disassortative (based on degree) word networks constructed through part-of-speech tags.

Regarding sentiment assortativity, we observe similar result to our previous work (Koncar and Helic 2019) where we constructed networks based on simple co-occurrences and found that networks are non-assortative. Here, sentiment assortativity lies between -0.02 and 0.07 for all networks. In any case, the results for sentiment assortativity suggest that positive and negative words are used randomly together and do not form any clusters based on their polarity. One plausible hypothesis for this observation could be that authors of spectator periodicals aimed at being impartial, which is possibly reflected in their explanations depicting both positive as well as negative aspects of the subject.

\section{Discussion}

Our analysis sheds light on the characteristics of sentiment conveyed by spectator periodicals published during the $18^{\text {th }}$ century. Assessing how sentiment evolves over time, we find that periodicals are, in general, rather stable over time and differences in sentiment are language-dependent and the individual periodicals themselves. It is, however, interesting that the polarity of mean sentiment across all languages is rather low, suggesting that authors succeeded in their aim to be neutral and impartial. This would be different to results of sentiment analyses on today's media, for which polarity is shown to be more extreme (Dos Rieis et al. 2015; Godbole et al. 2007), especially in cases of social conflicts in divided societies (Makrehchi 2014). However, note that this more extreme polarity may be an artifact of shorter texts analyzed in studies focusing on today's media. Typically, the ratio of sentiment words compared to non-sentiment words may be higher in shorter texts (e.g., a tweet) which, thus, results in a more polarizing sentiment as compared to longer texts (e.g., an issue of a periodical). To test whether or not text length influences the comparison between sentiment of spectator periodicals and sentiment of today's media, we 
compute the mean sentiment of all text passages with a maximum length of 280 characters (i.e., comparable to the length of a tweet) across all five languages. Here, we find a mean sentiment of 0.027 (95\% confidence intervals: 0.015 and 0.039 ), indicating that spectator periodicals may have been more neutral as compared to today's media. Nevertheless, we suggest an in-depth analysis of sentiment differences between spectator periodicals and today's media for future work.

Regarding the relation between sentiment and narrative forms, we find that our results are inconclusive. A potential explanation for this observation could be that narrative forms have been used by authors through different means, each with a different interpretation and incorporation of distinct styles. A further analysis of the different styles of authors is a promising subject for future work, and can be accomplished, for example, by authorship identification.

Our analysis on topics reveals both differences, such as disparate views on religion, and commonalities, such as a general more critical stance towards politics, among countries in Europe of the $18^{\text {th }}$ century. We observe that topics dealing with interpersonal relationships were perceived positively across countries, which may be due to the general tenor of treating other people with respect and the particular aim of spectator periodicals to increase the morality of their readers. In our analysis, we also report a critical discussion of foreign societies (especially in case of French and Spanish periodicals), which could indicate the rising nationalism during the $18^{\text {th }}$ century (Mann 1996).

Overall, our analysis sheds light on how important issues of the Age of Enlightenment were perceived by the people living during that time and contributes to the knowledge of the starting point of modern societies.

We further investigate how periodicals wrote about other periodicals and find mixed results. While Italian and Spanish periodicals were positive about other periodicals in these languages, French periodicals were rather negative about other French periodicals. Hence, drawing conclusions from these observations is vague and we suggest a more detailed analysis for future work, allowing us to learn more about how sentiment and information spread across periodicals.

The results from our sentiment word networks reveal differences and commonalities to our previous results produced with simple co-occurrence networks (Koncar and Helic 2019). While we observe higher local clustering coefficients for negative words in simple co-occurrence networks, we report the opposite behavior with our new sentiment word networks, suggesting that when considering semantic affinities, negative words form less local motifs in networks. Typically, words in networks form local clusters when they cooccur within the same local domains (e.g., focusing around one distinct topic or text passage). To us it seems that this is not the case with words conveying negative sentiment, further corroborating our initial hypothesis that negative words are used distinctively to discuss critical issues. We find a commonality in the top central words, for which we observe a weak overrepresentation of positive words in both sentiment word networks and simple co-occurrence networks which, combined with our results from degree distributions, suggest a general mild to positive tone in spectator periodicals.

Limitations. Our sentiment analysis of spectator periodicals is a challenging task, especially due to the absence of dedicated and comparable methods for $18^{\text {th }}$ century texts. It is therefore inevitable to fall back on existing methods (lemmatization and sentiment dictionaries). At the first glance one may argue that these existing methods are originally 
intended for modern day texts, and that there is no reason to believe that they yield valid results for $18^{\text {th }}$ century texts. Our coverage analysis, however, reveals that the majority of words in the used sentiment dictionaries indeed appeared in the respective texts, thus putting our analyses on solid grounds.

Additionally, the selection of other sentiment dictionaries may alter our results as suggested by previous research (Reagan et al. 2015). To assess if our results are robust with respect to the selection of sentiment dictionaries, we repeated our calculation of the development of the sentiment over time with a selection of alternative publicly available sentiment dictionaries ${ }^{8}$. In the case of French, we observe similar trends over the years but the mean polarity is shifted towards a more positive sentiment as compared to results from original dictionaries. For Italian and Spanish, we observe similar mean polarity and trends. Thus, we obtain qualitatively comparable results with the alternative selection of sentiment dictionaries. However, a more in-depth analysis on the influence of sentiment dictionaries on the quantitative results represents an interesting avenue for future research, potentially further strengthening our results.

Regarding potential issues with lemmatization for sentiment word networks conducted with models for modern day languages, we redid all related experiments without lemmatization. We find similar results for degree distributions, local clustering coefficients as well as degree and sentiment assortativity, albeit noticing a larger degree assortativity for the smaller German (0.43 compared to 0.22 ) and Portuguese (0.59 compared to 0.33 ) networks. In the case of centralities, we report similar ratios of positive and negative words among top central words of all centrality measures (with some variances in top central words). As such, we obtain qualitatively comparable results without lemmatization and suggest a detailed analysis on the impact of lemmatization for future work.

We nevertheless believe that the implementation of adjusted models could further improve the quality of analysis, and thus leave this task for future work. Further, we address the fact that our approach is data hungry, as our sentiment word networks only connect words if similarity is above a certain significance level, which can only be achieved if sufficient data is available. For example, the small corpus size of German and Portuguese texts resulted in these networks having multiple components, effectively leaving them useless for the analysis. The significance level also impacts the resulting sizes of networks and using other levels could alter the quantitative and qualitative results of the analysis of sentiment word networks. We tried an additional significance $(\alpha=0.05)$, but results varied only minimally for the three larger networks.

\section{Conclusion}

In this work, we conducted a three-fold analysis of sentiment conveyed by spectator periodicals published during the Age of Enlightenment. We first set our focus on the relation between sentiment and annotations contained in our multilingual dataset and found discrepancies across languages depending on narrative forms and the discussed topics. In the second part of our analysis we constructed sentiment networks to assess the relation between different entities. Here, we found a rather critical interaction between periodicals, positive references across countries but negative references in domestic cases, indicating a tendency of authors to be more critical with fellow countrymen, as well as

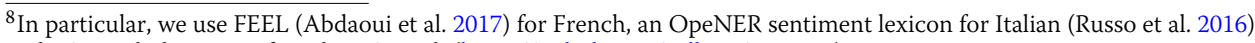
and a Spanish dictionary found on GitHub (https://github.com/aylliote/senti-py). 
a general positive tone between authors. Finally, we constructed sentiment word networks to study the differences between positive and negative word usages. Specifically, we observed low transitivity and a tendency towards low degrees for negative words as compared to positive ones which have higher probabilities for mid-range degrees as well as for higher transitivity. The weak overrepresentation of positive words among the most central words in networks combined with our results of degree distributions indicate a rather mild to positive tone across all periodicals in which critiques comprise a plethora of different negative words.

Our work serves as a basis for promising future work, for which we plan to implement dedicated sentiment dictionaries for the language of the $18^{\text {th }}$ century as well as the consideration of additional languages, such as Danish or Dutch spectator periodicals. Alternatively, other views on sentiment could be considered, for example, an existing machine learning approach to infer the emotional arcs of spectator periodicals (Reagan et al. 2016). Further, we are interested in detailed comparison of sentiment characteristics between today's media and the spectator periodicals from the Age of Enlightenment. In particular, we are interested in applying existing methods (Ferraz de Arruda et al. 2018) to study and compare the evolution of topics now and then.

Overall, this paper broadens our knowledge about spectator periodicals and demonstrates a distant reading method to analyze sentiment conveyed by them. The public availability of data and code for reproducibility lays the foundation for extended studies of spectator periodicals as well as other publications originating from the $18^{\text {th }}$ century.

\section{Abbreviations}

NLP: Natural language processing; VADER: Valence aware dictionary and sEntiment Reasoner; LIWC: Linguistic inquiry and word count; WNTM: Word network topic model; XML: Extensible Markup Language; TEl: Text encoding initiative; OAIS: Open archival information system; GAMS: Geisteswissenschaftliches asset management system; CDF: Cumulative distribution functions

\section{Acknowledgements}

The authors want to thank all members of the DiSpecs project for their fruitful input during the conduction of our experiments.

\section{Authors' contributions}

Authors from Graz University of Technology conducted the experiments and implemented the technical part of the analysis. Authors from University of Graz provided the expert knowledge to interpret the results. All author(s) read and approved the final manuscript.

\section{Funding}

This work was funded by the go!digital Next Generation programme of the Austrian Academy of Sciences and conducted as part of the DiSpecs (Distant Spectators: Distant reading for periodicals of the enlightenment) project.

\section{Availability of data and materials}

The dataset comprising the spectator periodicals is publicly available at https://gams.uni-graz.at/spectators. The code used to conduct our analysis is available at https://github.com/philkon/sentiment-spectator-extended.

\section{Competing interests}

The authors declare that they have no competing interests.

Author details
${ }^{1}$ Graz University of Technology, Graz, Austria. ${ }^{2}$ University of Graz, Graz, Austria. ${ }^{3}$ Know-Center GmbH, Graz, Austria.

Received: 11 March 2020 Accepted: 27 May 2020

Published online: 24 June 2020

\section{References}

Abdaoui A, Azé J, Bringay S, Poncelet P (2017) Feel: a french expanded emotion lexicon. Lang Resour Eval 51(3):833-855

Allan D, Virtue L (1993) The Scottish Enlightenment. Edinburgh University Press, Edinburgh

Amancio DR (2015) A complex network approach to stylometry. PloS ONE 10(8):0136076

Amancio DR, Nunes M. d. G. V., Oliveira Jr O, Pardo TAS, Antiqueira L, Costa L. d. F. (2011) Using metrics from complex networks to evaluate machine translation. Phys A Stat Mech Appl 390(1):131-142 
Amancio DR, Oliveira Jr ON, Costa LdF (2012) Unveiling the relationship between complex networks metrics and word senses. EPL 98(1):18002

Antiqueira L, Oliveira Jr ON, da Fontoura Costa L, Nunes MdGV (2009) A complex network approach to text summarization. Inf Sci 179(5):584-599

Astigarraga J (2015) The Spanish Enlightenment Revisited. Voltaire Foundation, Oxford

Beevers D (2008) Chinese Whispers: Chinoiserie in Britain, 1650-1930. Royal Pavilion Libraries \& Museums, Brighton

Bonferroni CE (1935) II calcolo delle assicurazioni su gruppi di teste. Studi in onore del professore salvatore ortu carboni,:13-60

Boulard C (2000) Presse et Socialisation Féminine en Angleterre de 1690 À 1750, Conversations À L'heure du Thé: Étude du Gentleman's Journal, du Spectator et du Female Spectator. Editions L'Harmattan, Paris

Cantwell GT, Newman M (2019) Mixing patterns and individual differences in networks. Phys Rev E 99(4):042306

Carr R (2014) Gender and Enlightenment Culture in Eighteenth-century Scotland. Edinburgh University Press, Edinburgh

Chen Q, Li C, Li W (2017) Modeling language discrepancy for cross-lingual sentiment analysis. In: Proceedings of the 2017 ACM on Conference on Information and Knowledge Management. ACM, New York. pp 117-126

Chen Y, Skiena S (2014) Building sentiment lexicons for all major languages. In: Proceedings of the 52nd Annual Meeting of the Association for Computational Linguistics (Volume 2: Short Papers). Association for Computational Linguistics, Baltimore. pp 383-389

Cong J, Liu H (2014) Approaching human language with complex networks. Phys Life Rev 11(4):598-618

Consortium T (2020) Guidelines for Electronic Text Encoding and Interchange. http://www.tei-c.org/P5/. Accessed 16 Feb 2020

Dill H-O (2015) Aufklärung Als Weltprojekt. Peter Lang, Bern, Switzerland

Dos Rieis JCS, de Souza FB, de Melo POSV, Prates RO, Kwak H, An J (2015) Breaking the news: First impressions matter on online news. In: Ninth International AAAI Conference on Web and Social Media. The AAAI Press, California

Ertler K-D (2003) Moralische Wochenschriften in Spanien: José Clavijo Y Fajardo: El Pensador. Gunter Narr Verlag, Tübingen

Ertler K-D (2004) Tugend und Vernunft in der Presse der Spanischen Aufklärung-El Censor. Gunter Narr Verlag, Tübingen

Ertler K-D, Fuchs A, Fischer M, Hobisch E, Scholger M, Völkl Y (2011) The Spectators in the international context. https:// gams.uni-graz.at/spectators. Accessed 16 Feb 2020

Ferraz de Arruda H, Nascimento Silva F, Queiroz Marinho V, Raphael Amancio D, da Fontoura Costa L (2018) Representation of texts as complex networks: a mesoscopic approach. J Compl Netw 6(1):125-144

Fischer-Pernkopf M, Mussner V, Ertler K-D (2018) Die "Spectators" in Frankreich: "Le Nouveau Spectateur" und "Le Monde Comme II Est" Von Jean-François de Bastide. Peter Lang, Bern. https://www.peterlang.com/view/title/68171

Fuchs A, Ertler K-D (2014) Die Moralischen Periodika in Italien: L'Osservatore veneto. Verlag Dr. Kovac, Hamburg

Fuchs A, Ertler K-D (2018) Kommunikative Inszenierung und Migration der Mikroerzählungen in der Gazzetta urbana veneta von Antonio Piazza. Verlag Dr. Kovac, Hamburg

Fuchs A, Ertler K-D, Holzer J (2019) Mikroerzählungen in den Spectators. Verlag Dr. Kovac, Hamburg

Gerlach M, Peixoto TP, Altmann EG (2018) A network approach to topic models. Sci Adv 4(7):1360

Gilot M, Sgard J (1981) Le journalisme masqué. Le journalisme d'ancien régime (Lyon) :285-313

Godbole N, Srinivasaiah M, Skiena S (2007) Large-scale sentiment analysis for news and blogs. Icwsm 7(21):219-222

Gómez Trueba T (1999) El sueño literario en españa. Madrid, Cátedra

Guinard P-J (1973) La presse espagnole de 1737 à 1791. Form et signification d'un genre, op. cit,:344

Gustafson WW (1932) The influence of the "tatler" and "spectator" in sweden. Scand Stud notes 12(4):65-72

Henny-Krahmer U (2018) Exploration of Sentiments and Genre in Spanish American Novels. https://dh2018.adho.org/ exploration-of-sentiments-and-genre-in-spanish-american-novels/. Accessed 16 Feb 2020

Honegger C (1991) Die Ordnung der Geschlechter: Die Wissenschaften Vom Menschen und Das Weib, 1750-1850. Campus, Frankfurt

Hösle J (1993) Carlo Goldoni. Piper Verlag GmbH, Munich

Hutto CJ, Gilbert E (2014) Vader: A parsimonious rule-based model for sentiment analysis of social media text. In: Eighth International AAAI Conference on Weblogs and Social Media. The AAAI Press, California

Jannidis F, Reger I, Zehe A, Becker M, Hettinger L, Hotho A (2016) Analyzing Features for the Detection of Happy Endings in German Novels. arXiv preprint arXiv: 1611.09028

Karimi F, Génois M, Wagner C, Singer P, Strohmaier M (2018) Homophily influences ranking of minorities in social networks. Sci Rep 8(1):11077

King RS (2018) All the news that's fit to write: The eighteenth-century manuscript newsletter. In: Travelling Chronicles: News and Newspapers from the Early Modern Period to the Eighteenth Century. Brill, Leiden. pp 95-118

Koncar P, Helic D (2019) Text sentiment in the age of enlightenment. In: International Conference on Complex Networks and Their Applications. Springer, Cham. pp 350-362

Krefting E (2018) News versus opinion: The state, the press, and the northern enlightenment. In: Travelling Chronicles: News and Newspapers from the Early Modern Period to the Eighteenth Century. Brill, Leiden. pp 299-318

Krefting E, Nøding A, Ringvej M (2015) Eighteenth-century Periodicals as Agents of Change: Perspectives on Northern Enlightenment. Brill, Leiden

Kulig A, Drożdż S, Kwapień J, Oświęcimka P (2015) Modeling the average shortest-path length in growth of word-adjacency networks. Phys Rev E 91(3):032810

Lévrier A (2007) Les Journaux de Marivaux et Le Monde des "spectateurs". Presses Paris Sorbonne, Paris

Liu Z, Huang W, Zheng Y, Sun M (2010) Automatic keyphrase extraction via topic decomposition. In: Proceedings of the 2010 Conference on Empirical Methods in Natural Language Processing. Association for Computer Linguistics, Cambridge. pp 366-376

Liu B, Zhang L (2012) A survey of opinion mining and sentiment analysis. In: Mining Text Data. Springer, Bosten. pp 415-463

López TE (2002) Prensa Clandestina Española del Siglo XVIII:" El Duende Crítico". vol. 24. Universidad de Valladolid, Valladolid

Maas AL, Daly RE, Pham PT, Huang D, Ng AY, Potts C (2011) Learning word vectors for sentiment analysis. In: Proceedings of the 49th Annual Meeting of the Association for Computational Linguistics: Human Language

Technologies-volume 1. Association for Computational Linguistics, Stroudsburg. pp 142-150 
Makrehchi M (2014) The correlation between language shift and social conflicts in polarized social media. vol. 2, In: 2014 IEEE/WIC/ACM International Joint Conferences on Web Intelligence (WI) and Intelligent Agent Technologies (IAT). IEEE, New Jersey. pp 166-171

Mann M (1996) The emergence of modern european nationalism. Poznan Stud Philos Sci Hum 48:147-170

Martens W (2017) Die Botschaft der Tugend: die Aufklärung Im Spiegel der Deutschen Moralischen Wochenschriften. Springer, Heidelberg

Melton JVH (2001) The Rise of the Public in Enlightenment Europe. Cambridge University Press, Cambridge

Messbarger R (1999) Reforming the female class: "il caffè" 's "defense of women". Eighteenth-century Stud 32(3):355-369

Montemurro MA, Zanette DH (2013) Keywords and co-occurrence patterns in the voynich manuscript: An information-theoretic analysis. PloS ONE 8(6)

Moreno-Ortiz A (2017) Lingmotif: Sentiment analysis for the digital humanities. In: Proceedings of the Software Demonstrations of the 15th Conference of the European Chapter of the Association for Computational Linguistics. Association for Computational Linguistics, Valencia, Spain. pp 73-76

Pallares-Burke ML (2007) The spectator, or the metamorphoses of the periodical: a study in cultural translation. In: Cultural translation in early modern Europe. Cambridge University Press, Cambridge. pp 142-159

Pang B, Lee L, et al (2008) Opinion mining and sentiment analysis. Found Trends ${ }^{\circledast}$ Inf Retr 2(1-2):1-135

Pang B, Lee L, Vaithyanathan S (2002) Thumbs up?: sentiment classification using machine learning techniques. In: Proceedings of the ACL-02 Conference on Empirical Methods in Natural Language processing-Volume 10. Association for Computational Linguistics, Pennsylvania. pp 79-86

Pennebaker JW, Francis ME, Booth RJ (2001) Linguistic inquiry and word count: Liwc 2001. Mahway: Lawrence Erlbaum Associates 71(2001):2001

Prettenhofer P, Stein B (2010) Cross-language text classification using structural correspondence learning. In: Proceedings of the 48th Annual Meeting of the Association for Computational Linguistics. Association for Computer Linguistics, Uppsala. pp 1118-1127

Rau F (1980) Zur Verbreitung und Nachahmung des Tatler und Spectator. vol. 145. C. Winter

Ravasz E, Barabási A-L (2003) Hierarchical organization in complex networks. Phys Rev E 67(2):026112

Reagan AJ, Mitchell L, Kiley D, Danforth CM, Dodds PS (2016) The emotional arcs of stories are dominated by six basic shapes. EPJ Data Sci 5(1):31

Reagan AJ, Tivnan B, Williams JR, Danforth CM, Dodds PS (2015) Benchmarking sentiment analysis methods for large-scale texts: a case for using continuum-scored words and word shift graphs. arXiv preprint arXiv:1512.00531

Rosa C (1966) Lo spectator ei giornali veneziani del settecento. Bari, Adriatica editrice

Roxas RM, Tapang G (2010) Prose and poetry classification and boundary detection using word adjacency network analysis. Int J Mod Phys C 21(04):503-512

Russo I, Frontini F, Quochi V (2016) Opener sentiment lexicon italian-Imf, ilc-cnr for clarin-it repository hosted at institute for computational linguistics "a. zampolli", national research council. Pisa 11752. http://hdl.handle.net/20.500

Schmidt T, Burghardt M (2018) Toward a tool for sentiment analysis for german historic plays. Laboratoire laussannois d'informatique et statistique textuelle, Lausanne

Schmidt T, Burghardt M, Wolff C (2018) Herausforderungen für sentiment analysis-verfahren bei literarischen texten. INF-DH-2018. Gesellschaft für Informatik eV, Bonn

Scholger M (2018) "Spectators" in the International Context - A Digital Scholarly Edition. In: Discourses on Economy in the Spectators. Verlag Dr. Kovac, Hamburg. pp 229-247

Shaver KG (2012) The Attribution of Blame: Causality, Responsibility, and Blameworthiness. Springer, New York

Silva TC, Amancio DR (2012) Word sense disambiguation via high order of learning in complex networks. EPL (Europhysics Letters) 98(5):58001

Sprugnoli R, Tonelli S, Marchetti A, Moretti G (2016) Towards sentiment analysis for historical texts. Digit Scholarsh Humanit 31(4):762-772

Steinbrügge L (2016) Das Moralische Geschlecht: Theorien und Literarische Entwürfe Über die Natur der Frau in der Französischen Aufklärung. Ergebnisse der Frauenforschung. vol. 11. Springer, Heidelberg

Thelwall M, Buckley K, Paltoglou G, Cai D, Kappas A (2010) Sentiment strength detection in short informal text. J Am Soc Inf Sci Technol 61(12):2544-2558

Vaussard M (2001) L'Italia Nel Settecento. Fabbri, Italy

Vellusig RH (2000) Schriftliche Gespräche: Briefkultur Im 18. Jahrhundert. vol. 54. Böhlau Verlag Wien, Vienna

Véronis J (2004) Hyperlex: lexical cartography for information retrieval. Comput Speech Lang 18(3):223-252

Von Tschilschke C (2009) Identität der Aufklärung-Aufklärung der Identität: Literatur und Identitätsdiskurs Im Spanien des 18. Jahrhunderts. vol. 9. Iberoamericana Editorial, Madrid

Weiner B (1995) Judgments of Responsibility: A Foundation for a Theory of Social Conduct. Guilford Press, New York

Widdows D, Dorow B (2002) A graph model for unsupervised lexical acquisition. In: Proceedings of the 19th International Conference on Computational linguistics-Volume 1. Association for Computational Linguistics, United States. pp 1-7

Xiao M, Guo Y (2013) Semi-supervised representation learning for cross-lingual text classification. In: Proceedings of the 2013 Conference on Empirical Methods in Natural Language Processing. Association for Computer Linguistics, Seattle. pp 1465-1475

Ye Q, Zhang Z, Law R (2009) Sentiment classification of online reviews to travel destinations by supervised machine learning approaches. Expert Syst Appl 36(3):6527-6535

Zhang L, Wang S, Liu B (2018) Deep learning for sentiment analysis: A survey. Wiley Interdiscip Rev Data Min Knowl Disc 8:1253

Zuo Y, Zhao J, Xu K (2016) Word network topic model: a simple but general solution for short and imbalanced texts. Knowl Inf Syst 48(2):379-398

\section{Publisher's Note}

Springer Nature remains neutral with regard to jurisdictional claims in published maps and institutional affiliations. 